\title{
Investigations on the spouting stability in a prismatic spouted bed and apparatus optimization
}

\section{Citation for published version (APA):}

Salikov, V., Heinrich, S., Antonyuk, S., Sutkar, V. S., Deen, N. G., \& Kuipers, J. A. M. (2015). Investigations on the spouting stability in a prismatic spouted bed and apparatus optimization. Advanced Powder Technology, 26(3), 718-733. https://doi.org/10.1016/j.apt.2015.02.011

\section{Document license:}

TAVERNE

DOI:

10.1016/j.apt.2015.02.011

Document status and date:

Published: 01/01/2015

\section{Document Version:}

Publisher's PDF, also known as Version of Record (includes final page, issue and volume numbers)

\section{Please check the document version of this publication:}

- A submitted manuscript is the version of the article upon submission and before peer-review. There can be important differences between the submitted version and the official published version of record. People interested in the research are advised to contact the author for the final version of the publication, or visit the $\mathrm{DOI}$ to the publisher's website.

- The final author version and the galley proof are versions of the publication after peer review.

- The final published version features the final layout of the paper including the volume, issue and page numbers.

Link to publication

\section{General rights}

Copyright and moral rights for the publications made accessible in the public portal are retained by the authors and/or other copyright owners and it is a condition of accessing publications that users recognise and abide by the legal requirements associated with these rights.

- Users may download and print one copy of any publication from the public portal for the purpose of private study or research.

- You may not further distribute the material or use it for any profit-making activity or commercial gain

- You may freely distribute the URL identifying the publication in the public portal.

If the publication is distributed under the terms of Article 25fa of the Dutch Copyright Act, indicated by the "Taverne" license above, please follow below link for the End User Agreement:

www.tue.nl/taverne

Take down policy

If you believe that this document breaches copyright please contact us at:

openaccess@tue.nl

providing details and we will investigate your claim. 
Original Research Paper

\title{
Investigations on the spouting stability in a prismatic spouted bed and apparatus optimization
}

\author{
Vitalij Salikov $^{a}$, Stefan Heinrich ${ }^{\mathrm{a}, *}$, Sergiy Antonyuk ${ }^{\mathrm{b}}$, Vinayak S. Sutkar ${ }^{\mathrm{c}}$, Niels G. Deen ${ }^{\mathrm{c}}$, J.A.M. Kuipers ${ }^{\mathrm{c}}$ \\ ${ }^{a}$ Institute of Solids Process Engineering and Particle Technology, Hamburg University of Technology, 21073 Hamburg, Germany

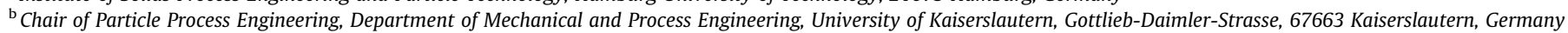 \\ ${ }^{\mathrm{c}}$ Multiphase Reactors Group, Department of Chemical Engineering and Chemistry, Eindhoven University of Technology, P.O. Box 513, 5600 MB Eindhoven, The Netherlands
}

\section{A R T I C L E I N F O}

\section{Article history:}

Received 27 September 2014

Received in revised form 14 February 2015

Accepted 19 February 2015

Available online 4 March 2015

\section{Keywords:}

Prismatic spouted bed

Spouting stability

Draft plates

Pressure drop fluctuations

\begin{abstract}
A B S T R A C T
This paper deals especially with spouting stability in a slot-rectangular (prismatic) spouted bed. The flow stability was characterized by the pressure drop evaluation (the uniformity and amplitude of the fluctuations) and visual observations (the flow symmetry). The effect of several geometrical conditions, such as the inlet design, prismatic angle and draft plates on the bed behaviour was investigated for different particles and bed inventories exposed to different air flow rates. The prismatic angle was found to have a strong impact on the spouting characteristics. A method to improve significantly the spouting quality and to make the spouting stability independent on the gas inflow velocity is presented. Compared to the reference geometry the prismatic angle was changed to a higher value and the apparatus was equipped with draft plates. Whereas, to achieve a stable spouting in a wide range of the air flow rates the design of draft plates should be customized to the bed inventory. Dependent on the static bed height full or open-sided draft plates should be used. In the proposed apparatus implementation, the maximum spouting velocity was almost eliminated for large particles (Geldart D), i.e. a highly coherent dense spouting can pass continuously into the dilute-like stable regime, without stability loss at intermediate gas velocities. The spouting of Geldart B particles is also improved.

(c) 2015 The Society of Powder Technology Japan. Published by Elsevier B.V. and The Society of Powder
\end{abstract} Technology Japan. All rights reserved.

\section{Introduction}

Gas-spouted beds have a broad application spectrum in traditional industries, as well as a potential for innovative applications concerning solids' processing (e.g. [1,2]). The reported applications of spouted beds are (amongst others) the mixing, heating/cooling, drying, coating, granulation and chemical reactions, and the related industries are the chemical and electrochemical, metallurgy, food and agricultural, pharmaceutical, as well as energy and nuclear industries [3]. Spouted beds are also well capable for the treatment of irregularly shaped solids [4]. In dependence on the apparatus geometry (circular or rectangular), spouted beds can be sub-divided into conventional conical-cylindrical and entirely conical beds, as well as slot-rectangular and two-dimensional ones. The spouted bed investigated in this work has a rectangular cross-section and substantial apparatus depth (or thickness) and can be affiliated with the family of slot-rectangular

\footnotetext{
* Corresponding author. Tel.: +49 04042878 3750; fax: +49 040428782678

E-mail address: stefan.heinrich@tuhh.de (S. Heinrich).
}

beds. An axisymmetric apparatus operated with static bed heights within the cone region is usually referred as a conical spouted bed. Similarly, we term this slot-rectangular geometry prismatic, since the used static bed does not usually exceed the prismatic apparatus region. The specific feature of the investigated apparatus is the gas supply through two thin horizontal slits, whereas the gas is introduced tangentially and deflected in the vertical direction by a central profile [5]. The spouting is in general sensitive to the inlet size (inlet to particle size ratio and inlet to bed size ratio) [4]. In the apparatus dealt with in this work the height of the slits is adjustable in the range of $0-3.5 \mathrm{~mm}$ by rotation of partially flattened cylinders; this is virtually a variation from thin to very thin slits. This adjustability of the inlets' size has some advantages in the application, e.g. flexibility in finding a suitable inlet size for spouting of solids, which are difficult to handle, or for different bed inventories. The apparatus can be comfortably filled with particles by keeping the gas inlets closed. Moreover, the clogging of the apparatus bottom area by cohesive particles can often be eliminated by temporary changing the inlets' size without a process interruption or increasing the gas flow rate. The bed is operated by underpressure, i.e. the gas is sucked through the apparatus. 


\section{Nomenclature}

$d_{\mathrm{p}} \quad$ particle diameter $(\mathrm{mm})$

$h \quad$ inlet height $(\mathrm{mm})$

$H \quad$ inlet-to-bed size ratio (-)

$H_{\text {fr }} \quad$ height of apparatus freeboard ( $\left.\mathrm{mm}\right)$

$H_{\text {pl_bottom }}$ positioning height of the bottom pair of draft plates (mm)

$h_{\text {pl_bottom }}$ length of the bottom pair of draft plates $(\mathrm{mm})$

$H_{\text {pl_top }}$

$h_{\text {pl_top }}$ positioning height of the top pair of draft plates $(\mathrm{mm})$ length of the top pair of draft plates (mm)

$H_{\text {st }}$ height of the particle bed under static conditions (mm)

$m \quad$ mass $(\mathrm{kg})$

max STD maximum value of standard deviation of operating pressure drop signal $(\mathrm{Pa})$
$R e_{\mathrm{p} \_ \text {in }} \quad$ particle Reynolds number in the area of gas inlet (-)

$v_{\text {g_in }} \quad$ gas velocity at gas inlets $(\mathrm{m} / \mathrm{s})$

$\dot{V} \quad$ air flow rate $\left(\mathrm{m}^{3} / \mathrm{s}\right)$

$W_{\text {pl_bottom }}$ inner distance between bottom draft plates $(\mathrm{mm})$

$W_{\mathrm{pl} \_ \text {top }} \quad$ inner distance between top draft plates $(\mathrm{mm})$

\section{Greek letters}

$\alpha \quad$ apparatus width (m)

$\beta \quad$ apparatus depth (m)

$\gamma \quad$ inclination angle of bottom draft plate $\left(^{\circ}\right)$

$\mu_{\mathrm{g}} \quad$ dynamic gas viscosity $(\mathrm{kg} /(\mathrm{m} \mathrm{s}))$

$\rho_{\mathrm{g}} \quad$ gas density $\left(\mathrm{kg} / \mathrm{m}^{3}\right)$

$\theta \quad$ included angle of prismatic region $\left(^{\circ}\right)$.
This spouted beds design was adopted by industry and applied for lab, pilot and industrial scale plants for batch and continuous agglomeration, film and powder coating, spray granulation, and encapsulation (ProCell spouted bed technology in [6]). This meanwhile established apparatus design which is reasonably appropriate for many applications was used in this work as a reference (starting) geometry. Due to the diversity of applications and different types of solids, the optimal implementation of a process demands appropriately designed "tailored" beds. For instance a further development of this apparatus concept was a purposedesigned spouted bed for treatment of fine and light solids, such as aerogel particles for pharmacy [7] and $\mu \mathrm{m}$-sized ceramic and sub-structured composite particles for a material science application $[1,2]$. This spouted bed has a small prismatic process chamber with adjustable gas inlets and a large and steep freeboard and is usually operated in dilute spouting regime.

The main aim of this work was a further development and improvement of this spouted bed concept with regard to improve the spouting stability in the dense spouting range. This apparatus has a stable operation range limited by applicable gas flow rate and the particle inventory. The main aim of the work presented here was to find a possibility to enlarge this range towards increased gas velocities and static bed heights, i.e. to achieve a simultaneously intense and uniform particle circulation within a wide range of gas velocity by optimizing of the apparatus geometry. For this purpose the influence of the shape of the central profile, prismatic angle and draft plates on spouting stability was investigated and the obtained results were condensed in a geometry "tailored" on increased flow stability.

\section{Background}

\subsection{Spouting stability}

There exist two stable flow regimes in spouted beds (Fig. 1): one in the dense and the second in the dilute range of the granular flow correspondingly termed the (dense) spouting and dilute or jet spouting [8]. Under stable operating conditions the granular flow in a spouted bed appears as characteristic uniform circulating patterns. A particle bed in the state of the dense spouting shows several distinct regions of different particle dynamics: (i) an upwards directed rather dilute spout formed by fast ascending particles, (ii) the dense annulus region, where the solids slowly flow downwards, and (iii) the fountain region, where the particles change the movement direction under the influence of the gravity. For the dilute spouting high gas velocity and high bed voidage are characteristic. The characteristic cyclic particle movement is also maintained in this regime. Spouted beds provide an effective solid-fluid contact and a good heat and mass transfer, whereas the uniform circulation enables the product homogeneity [9]. Mathur and Epstein pointed out, that the flow stability in spouted beds depends on: (i) the static particle bed height, (ii) the solids properties, such as the interparticle friction, particle size and size distribution, (iii) the ratio of the inlet to bed diameter, (iv) the cone angle, as well as (v) the gas velocity [4]. For instance, for a given apparatus geometry and particle properties the stable spouting region (if one exists) is limited by the particle amount (this should be in the range between the minimum and maximum spoutable bed heights). Furthermore, the stable spouting appears only in a limited interval of gas velocities (the range between the minimum and maximum spouting velocities). Mathur and Epstein specified in [4] three mechanisms of the spout termination, responsible for the existence of the upper limit of the particle inventory, which can be spouted in conventional conical-cylindrical apparatuses, as: (i) fluidization of annular solids, (ii) chocking of the spout, and (iii) growth of instabilities at the spout-annulus interface. The dilute spouting range is located between the minimum dilute spouting velocity and particle elutriation from the apparatus.

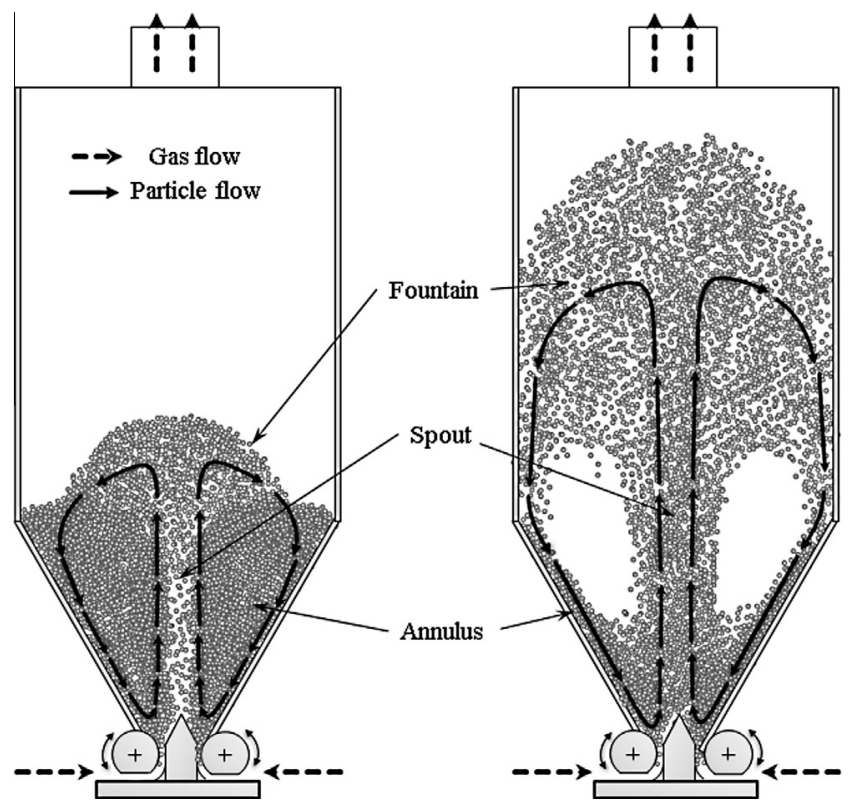

Fig. 1. A schematic representation of stable spouting regimes: left (dense) spouting; right dilute spouting. 


\subsection{Prismatic apparatus}

The previous experimental studies on hydrodynamics of this prismatic geometry comprehend the influence of the gas flow rate, solids' properties and inventory, as well as of the inlet size [10-13].

In the following, findings relevant in the context of spouting stability (and intensity) will be discussed in more detail. In the experimental investigations by Gryczka et al. [10] the apparatus with prismatic angle of $60^{\circ}$ was characterized. It was found that to achieve stable spouting conditions the static height of the particle bed should not exceed the height of the prismatic region. The range of an inlet-to-bed size ratio, where the initiation of stable spouting in this apparatus is possible, was identified and correlated with the Archimedes number of particles. Outside of this range, different unstable fluidization regimes were found and the stable dense spouting did not appear at all. The increase in the gas flow rate is the simplest possibility to increase the particle velocities, i.e. to achieve a more intense (vigorous) spouting. Furthermore, the particle rotation is simultaneously increased to some extent, as found experimentally in [12] by means of magnet monitoring and by means of simulations with Discrete Particle Modelling (DPM) in $[11,13]$. However, regarding to the behaviour at increased gas velocities a negative property of this geometry was complained, namely a quickly growing flow instability, making the spouting stability highly dependent on the gas flow rate [10]. In our recent combined study (DPM and experiment) the behaviour of this apparatus under conditions of increasing gas flow rate was treated in more detail [11]. The appearance of the dilute spouting regime at high gas velocities was also proven for this spouted bed type. Both stable regimes shown schematically in Fig. 1 are separated by an instable region at intermediate gas velocities, which has a substantial extension. Fig. 2 shows a typical regime map for Geldart D particles with corresponding flow patterns [11]. In this diagram, the particle Reynolds number at the gas inlets $R e_{\mathrm{p}_{-} \text {in }}$ (Eq. (1)) as the ordinate and an inlet-to-bed size ratio $H$ (Eq. (2)) as the abscissa are used, as specified in [11].

$R e_{\mathrm{p} \_ \text {in }}=\frac{v_{\mathrm{g} \_ \text {in }} d_{\mathrm{p}} \rho_{\mathrm{g}}}{\mu_{\mathrm{g}}}$,

$H=2 h / H_{\text {st }}$

where $v_{\mathrm{g} \_ \text {in }}$ is the gas velocity at inlets, $d_{\mathrm{p}}$ the particle size, $\rho_{\mathrm{g}}$ the gas density and $\mu_{\mathrm{g}}$ is the dynamic gas viscosity. $H$ is the ratio between the inlet width (summed height of both slits) $2 h$ and the static particle bed height $H_{\text {st }}$. Two stable spouting regimes (the dense and the dilute) are separated by an instable region in the range of intermediate gas velocities (Reynolds numbers). The transitions of the particle bed state occurring under conditions of increasing air flow rate and the corresponding pressure drop behaviour in the prismatic apparatus can be described as the following $[10,11]$ :

\subsubsection{Fixed bed and internal cavity (FB)}

The particle bed remains fixed for a while until a certain gas velocity at which a small cavity is forming above the gas inlet. With increasing air flow rate the cavity grows and the particle bed expands slightly.

\subsubsection{Irregular bubbling (IB)}

At a certain air flow rate the inlet overpressure becomes high enough to push the first bubble though the particle bed. After that, the gas inlet is immediately blocked by the particles sliding down from the annulus area. This causes an anew growth of the inlet overpressure and the formation of the next bubble. The produced bubbles differ in size and arise in different time intervals; therefore the pressure drop fluctuates at irregular manner with low frequencies $(<4 \mathrm{~Hz})$. This behaviour remains consistent for an interval of the air flow rate. However, at higher gas flow rates in this interval the regularity of the pressure signal grows, which causes a narrowing of the distribution of the Fast Fourier Transform (FFT) power function. Simultaneously the main frequency travels to higher values.

\subsubsection{Stable "dense" spouting $(S)$}

At the minimum spouting velocity a spout is formed. In this flow state, the gas fluctuations show similar amplitudes and occur in regular time intervals, which results in a single quite narrow peak in the FFT power plot. The origin of the regular pressure fluctuations are the periodic oscillations in the spout cross-section, as described in [11]. The particle flow is similar to the "multiple spouting" type previously described by Freitas et al. [14] and Chen [15] for slot-rectangular beds with a single vertical gas inlet. When the gas flow rate is further increased, the fluctuations remain regular for a while. However, at a certain point, slight periodical alternating spout deflections to the left and to the right of the central axis arise. Initially the spout deflections have a low influence on the pressure drop fluctuations. However, these deflections grow in the intensity with increasing gas flow rate and the particle flow becomes progressively less structured and pressure drop behaviour becomes progressively affected.

\subsubsection{Instable region (IR)}

The alternating spout deflections become very pronounced. The bed and pressure drop behaviour becomes progressively chaotic. At high gas flow rates in this range the spout deflections to the left and to the right lose their periodicity and a large amount of the bed material can be accumulated temporarily on one side of the apparatus. The flow structure of a spouted bed with regular circulating patterns is terminated. The particle motion shows random events such as spontaneous pulsations (changes in the bed expansion). The pressure drop fluctuates with different amplitudes and frequencies, which become apparent in additional high peaks in the FFT frequency domain.

\subsubsection{Stable "dilute" (or jet) spouting (DS)}

At high gas velocities a second reorganization (stabilization) of the particle flow can take place. Although, the particles are highly dispersed in the apparatus, the particle circulation typical for a spouted bed can be recognized. No oscillations or deflections of the central jet can be observed. This spouting state can be identified in the frequency domain by absence of other peaks as measured in the empty apparatus in the corresponding interval of the air flow rates.

Besides the gas velocity further factors have an effect on the spouting stability, such as the prismatic angle and the solids' frictional properties, as shown in a numerical investigation in [13]. The DPM simulations performed in that work yielded that a higher particle friction has a stabilising effect and a reduction of the (included) prismatic angle can cause flow instabilities.

\subsection{Draft tubes and plates}

Much work was done in the past on the study of the influence of different inserts in spouted and spout-fluidized beds. Insertion of draft tubes or plates changes the spouted bed hydrodynamics significantly. The minimum spouting velocity, operating pressure drop, solid circulation patterns, particle cycle times, and gas distribution are concerned [16]. The draft tubes can improve the apparatus performance, e.g. enhance the spouting of fine particles [17], and increase the maximum spoutable bed height [16]. For entirely conical spouted beds several configurations of draft tubes 


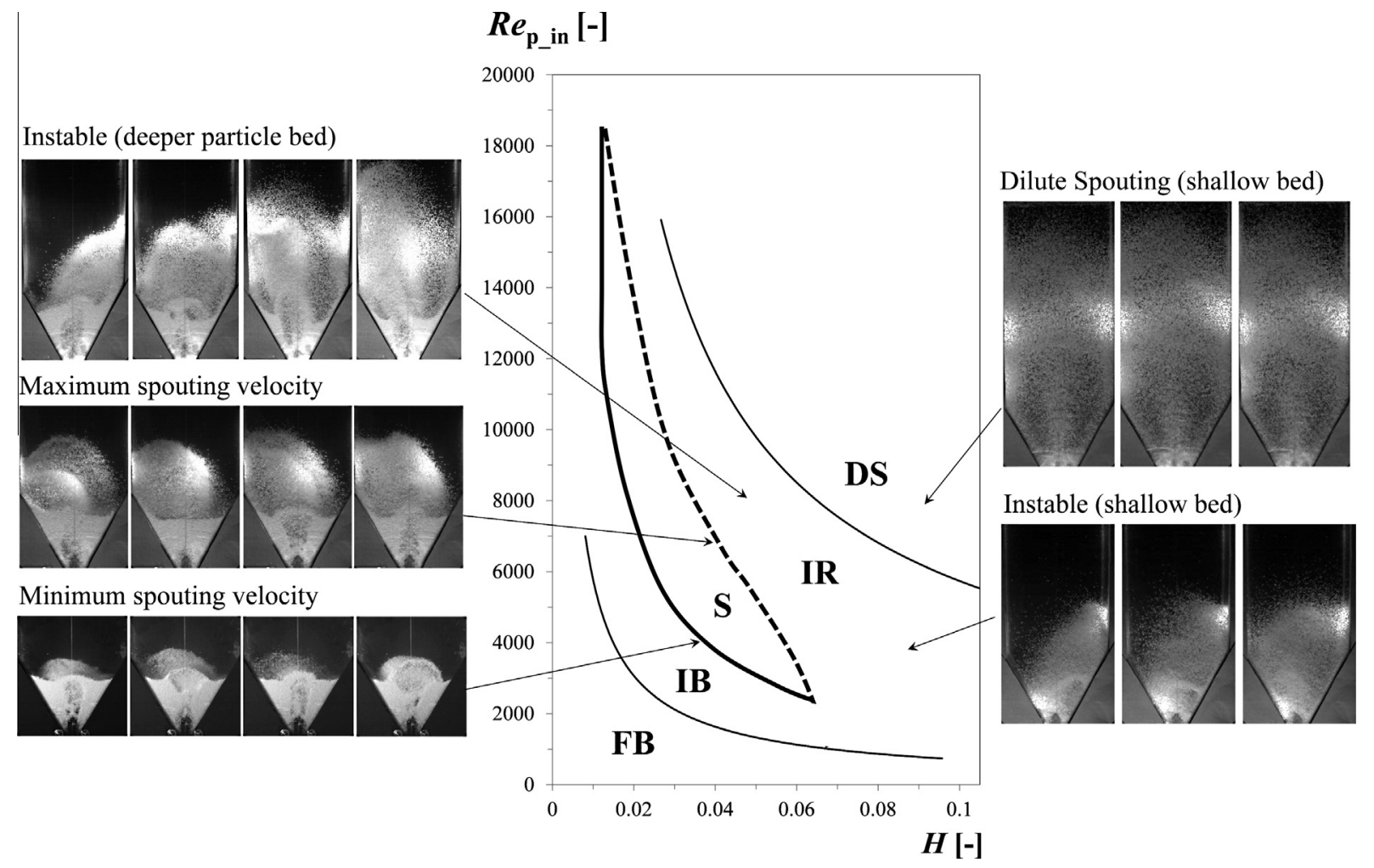

Fig. 2. Regime map for $\gamma-\mathrm{Al}_{2} \mathrm{O}_{3}$ particles with mean size of $1.77 \mathrm{~mm}$ (based on [11]).

were applied: the nonporous and porous as well as open-sided ones $[18,19]$. The latter were proven to be especially suitable for an enhanced contact. This configuration allows for a better gas distribution across the bed and higher solid circulation rates due to an enhanced solid cross-flow from the annulus area into the spout. For the conical apparatus equipped with open-sided draft tubes an improved drying performance was found in comparison with other tubes' configurations [18]. The insertion of draft plates in two-dimensional and slot-rectangular beds was investigated experimentally by Kalwar et al. [20-22] and Luo et al. [23] accented that a slot-rectangular spouted bed with draft plates is one of the most promising spouted bed configurations but stability issues were also reported. A more detailed overview on investigations on draft tubes or plates in spouted and spout-fluidized beds can be found in [24].

\section{Materials and methods}

\subsection{Experimental setup and materials}

A transparent experimental setup with an "adjustable" geometry was installed. A polycarbonate coated with a scratch-resistant and antistatic layer (Europlex ${ }^{\circledR}$ SDX, Evonik, Germany) was used as wall material. The 3D drawing of the experimental setup and a flow chart are shown in Fig. 3 a and b. Ambient air was sucked through the apparatus by means of an exhaust fan (SKG 420-2V, Elmo Ritschle, Germany) and the throughput was regulated by a frequency converter. The flow rate was calculated from air velocity, measured by using of an anemometer (EE65, E+E Elektronik, Austria) in the connecting pipe between the gas outlet and the fan. The snapshots were captured by means of a high-speed camera (MotionPro Y4, Imaging Solutions, Germany). Since the apparatus is operated in a sucking mode. The pressure drop was measured above the particle bed (in apparatus freeboard about $150 \mathrm{~mm}$ below the apparatus top, displaced $75 \mathrm{~mm}$ laterally from the central axis of the outlet orifice).by means of a high-speed sensor (differential pressure detector PD-23/8666.1, Keller, Germany). The sensor was connected to a signal convertor and a data acquisition system. The sampling frequency of $0.5 \mathrm{kHz}$ was used for measurement intervals of $20 \mathrm{~s}$. The recorded pressure time series were analysed by using the FFT algorithm in Matlab, whereas the first 8192 sampling points $\left(=2^{13}\right)$ were used. The number of sample points is determined by the FFT algorithm, which needs the number of data points of $2^{n}$ length. The height of the gas inlet slits was varied between 1, 2, 3 and $3.5 \mathrm{~mm}$ (full opening). Initially the flow behaviour in the "starting" geometry, described in $[10,11]$ (prismatic angle $\theta$ of $60^{\circ}$ and original "sharp" central profile, shown in Fig. 3c) was characterized. In Table 1 some physical properties of the used solids are summarized. In our previous investigation [11], $\gamma-\mathrm{Al}_{2} \mathrm{O}_{3}$ particles with $d_{\mathrm{p}} \sim 1.8 \mathrm{~mm}$ and a density of $1040 \mathrm{~kg} / \mathrm{m}^{3}$ were used in experiments and modelled. In this work this was extended for particles with different properties. The used glass particles are of similar size compared to $\gamma-\mathrm{Al}_{2} \mathrm{O}_{3}$ from previous work, but have a higher density; the polypropylene and finer $\gamma-\mathrm{Al}_{2} \mathrm{O}_{3}$ particles have a similar density but quite different size. The used solids are of type B and D in the Geldart classification [25]. All particles are closely sized and nearly spherical. Two shapes of the central profile were compared regarding to the influence on the spouting stability: the original "sharp" profile, used in $[10,11]$, and a "smoothed" one shown in Fig. 3c. After this, the prismatic angle was changed to $40^{\circ}, 50^{\circ}$ and $80^{\circ}$, to investigate the influence on the flow stability. The freeboard width $\alpha$, the apparatus depth $\beta$ and overall apparatus height were hold constant. After each variation in the apparatus geometry, the setup was sealed with a silicone to avoid gas leakages. The air flow rate and bed inventory were varied for each apparatus configuration and particle type. Several configurations of draft plates were installed to study the impact on the flow stability. The draft plates were made from the same polycarbonate as used for the apparatus walls with a thickness of $10 \mathrm{~mm}$. 
(a)

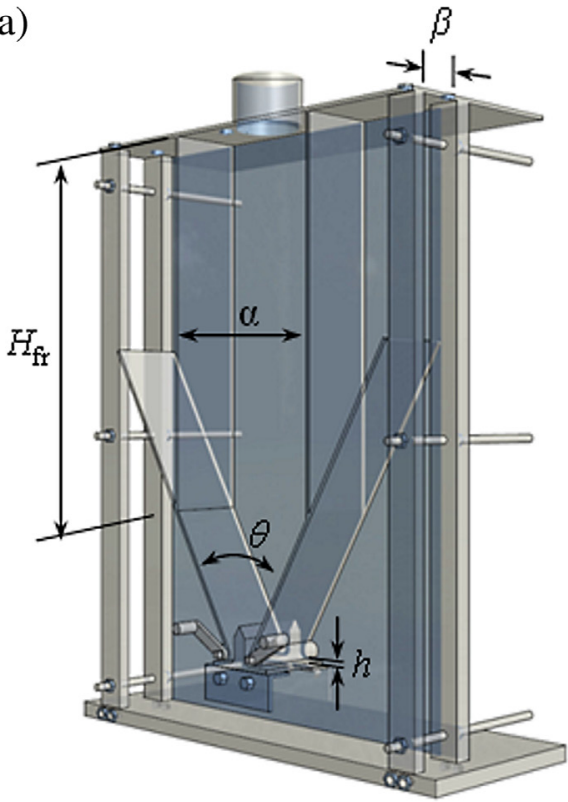

(b)

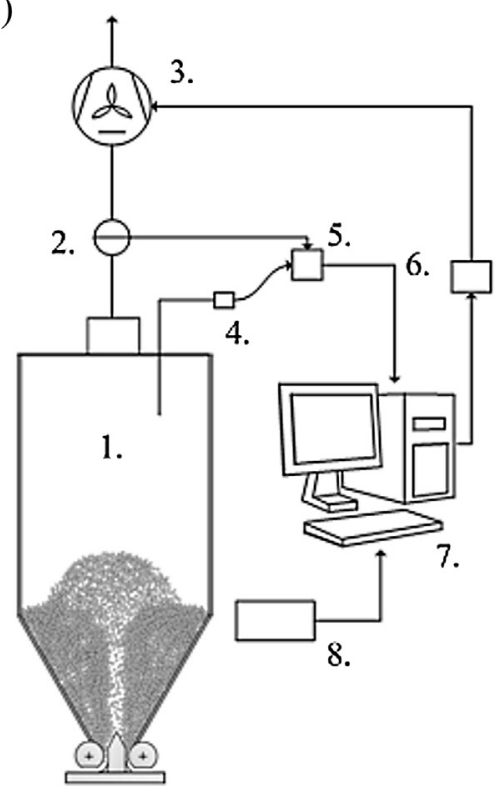

(c)

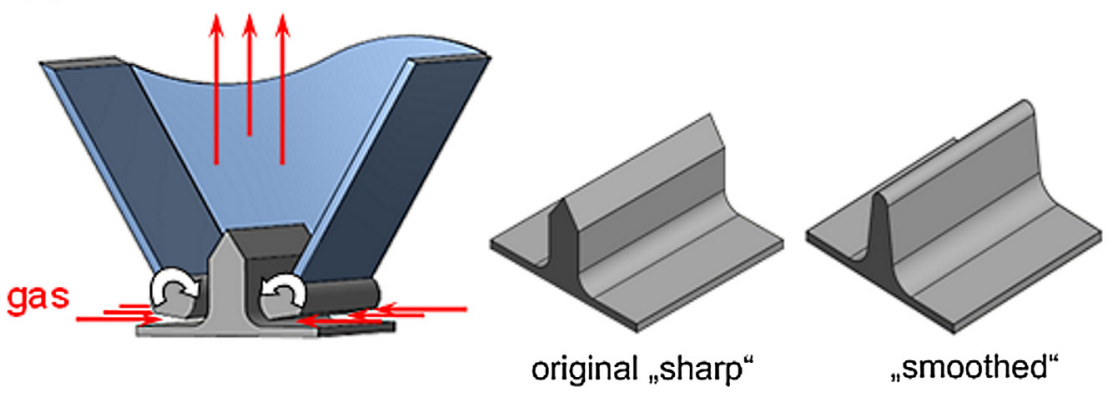

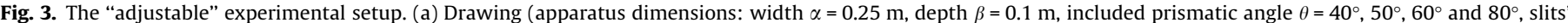

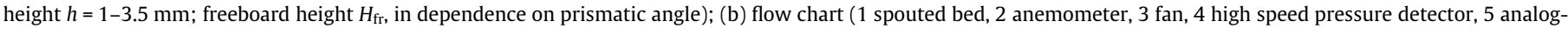
to-digital converter, 6 frequency converter, 7 computer, 8 high speed video camera; (c) inlet design and used shapes of the central profile.

Table 1

Properties of used particles.

\begin{tabular}{lllll}
\hline Particles & $\begin{array}{l}\text { Size } \\
(\mathrm{mm})\end{array}$ & $\begin{array}{l}\text { Density } \\
\left(\mathrm{g} / \mathrm{cm}^{3}\right)\end{array}$ & $\begin{array}{l}\text { Sphericity } \\
(-)\end{array}$ & $\begin{array}{l}\text { Geldart } \\
\text { type }\end{array}$ \\
\hline$\gamma-\mathrm{Al}_{2} \mathrm{O}_{3}$ & $1.77 \pm 0.14^{\mathrm{a}}$ & 1.04 & 0.98 & $\mathrm{D}$ \\
& $0.65 \pm 0.12$ & 1.04 & 0.97 & $\mathrm{~B}$ \\
Glass & $1.57 \pm 0.26$ & 2.5 & 0.98 & $\mathrm{D}$ \\
Polypropylene & $4.40 \pm 0.29$ & 0.91 & 0.93 & $\mathrm{D}$ \\
\hline
\end{tabular}

a \pm Standard deviations.

\subsection{Determination of stability}

The spouting stability and the range, where the stable dense spouting appears, were identified by evaluation of the pressure drop behaviour and visual observations. The used criteria were (i) flow symmetry by visual assessment, as well as (ii) the uniformity and (iii) the amplitude of the pressure drop fluctuations. These criteria are based mainly on the investigations on slot-rectangular bed with one vertical gas inlet by Chen [15] and previous work on the prismatic geometry by Gryczka et al. and Salikov et al. [10,11]. According to Chen an ideal stable spouted bed can be characterized by a steady-state, symmetrical and smooth particle flow [15].

\subsubsection{Visual observation}

In case of an ideally stable spouting the operating conditions should remain constant over time [15], i.e. the particles should permanently pass through similar flow patterns. The distribution of the solids in apparatus should be symmetrical, as well as the spout should be continuous and remain at the same position. The best possibility for the visual assessment of spouting stability is the observation of the fountain behaviour: the fountain shape should remain symmetrical, and its position as well as height constant over time.

\subsubsection{Uniformity of pressure drop fluctuations}

Gryczka et al. correlated the state of the stable spouting in the prismatic apparatus (in the dense flow range) with uniform pressure drop fluctuations, i.e. the fluctuations with nearly the same frequency and amplitude [10]. That is if the spouting takes place, the characteristic fluctuations will clearly dominate the signal, which would result in a high narrow peak at the corresponding frequency in the frequency domain. The characteristic frequencies are usually located in a range of $4-10 \mathrm{~Hz}$ [e.g. [10, 11, 15, 26], and [27]]. At gas flow rates outside the window of the stable dense spouting, the flow instabilities produce perturbances in the pressure signal, which result in additional peaks of not-negligible heights or in a broad distribution of the power function. Fig. 4 demonstrates some exemplary measurements for different particles and static bed heights in the starting geometry. In Fig. 4a several pressure time series and corresponding FFT power plots are shown for glass particles. For the used static bed height and particles there is a range of air flow rate $\left(\sim 0.04 \ldots 0.045 \mathrm{~m}^{3} / \mathrm{s}\right.$, 
(a)
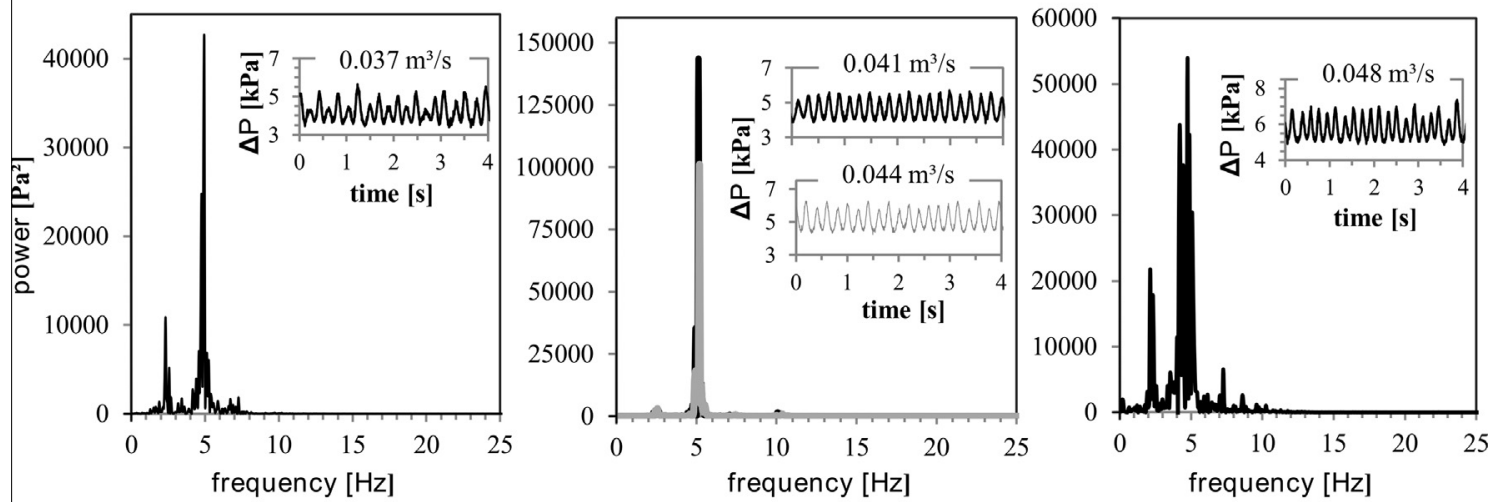

(b)
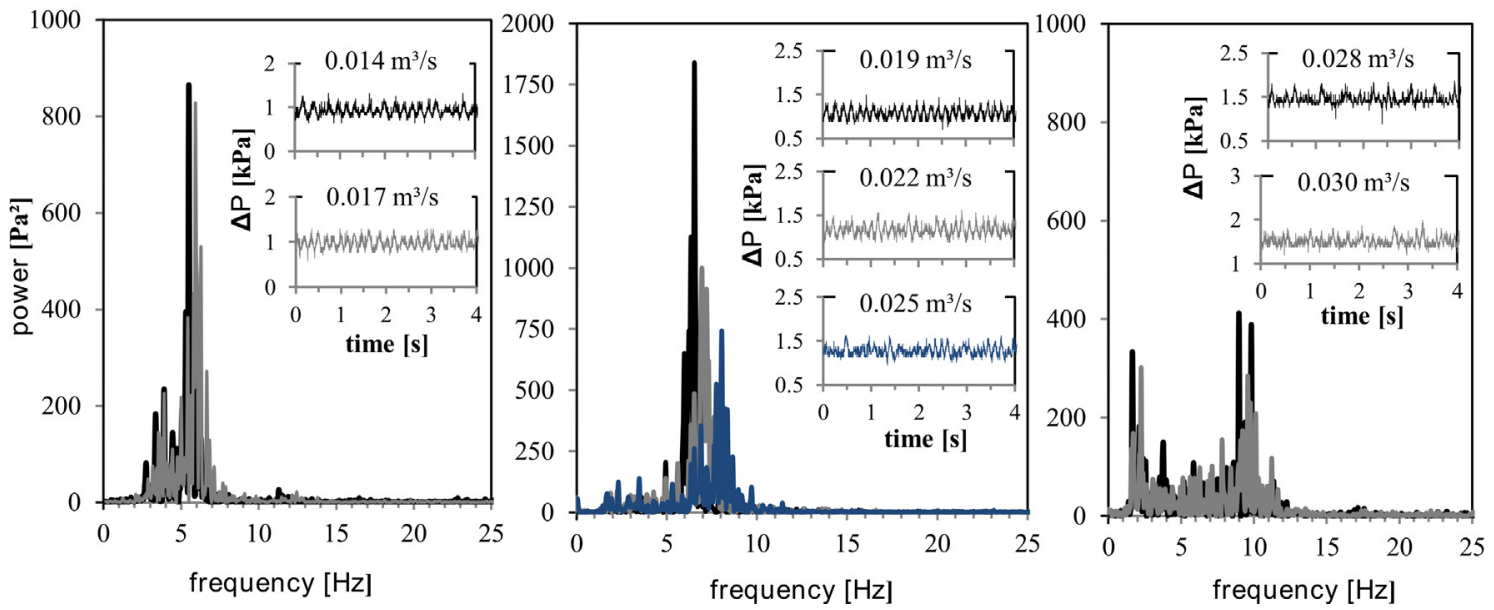

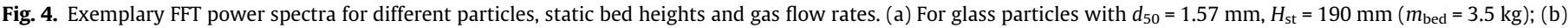

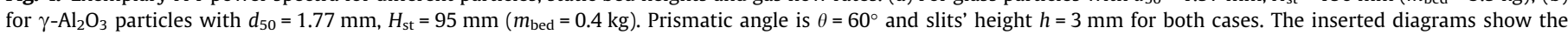
corresponding pressure drop time series (the first $4 \mathrm{~s}$ of captured signals, respectively).

two exemplary measurements are shown in the middle figure), where the pressure fluctuates uniformly with frequency of about $5 \mathrm{~Hz}$. The FFT power plots obtained for time series at lower and higher air flow rates shows a higher scatter of the frequencies. Fig. 4b shows in contrast the pressure drop behaviour for conditions where the range of the gas flow rate with uniform pressure drop fluctuations is still absent because the used static bed is outside of the spoutable range (here below the minimum spoutable value). For a correct interpretation of the pressure drop behaviour, it should also be noted, that the pressure drop signal is corrupted by the sensor noise and pressure fluctuations produced by gas supply. Fig. 5 shows the time series and FFT power spectra obtained for an empty geometry. The signal captured without an air supply is depicted in Fig. 5 on the left. The pure sensor noise is completely random and does not produce characteristic peaks at certain frequencies in the spectrum. But, at elevated air flow rates significant gas pressure fluctuations can be measured also in the empty apparatus. However, these can be clearly distinguished from the fluctuations produced by particles by their frequencies. The fluctuations measured in the empty apparatus are located in the range of 25-60 Hz. However, as mentioned above, much smaller frequencies in the range of $4-10 \mathrm{~Hz}$ are characteristic for spouting.

\subsubsection{Amplitude of the pressure drop fluctuations}

The uniformity of the pressure drop fluctuations reveals that similar events occur in the bed in a periodical manner and the frequency provides information about how often this takes place in a time interval. For evaluation of the influence of the geometrical conditions on the spouting coherence (smoothness) the amplitude of the pressure drop fluctuations was additionally examined. In this work we valued an increase in the amplitude of the bed and pressure fluctuations as a trend towards flow destabilization. Apparently, an ideally continuous particle circulation should not produce significant fluctuations. However, Chen assumed the particle flow in a slot-rectangular spouted bed to be always accompanied by fluctuations [15]. Therefore for these beds, a steady-state spouting with minimal fluctuations was considered as the most stable case. Dogan et al. [28] described the distinct incoherent spouting as a regime with extreme bed pulsations and periodical cluster-wise entrainment of particles in the spout. This results in a fountain having a pulsating variable height and intermittent particle flow in the upper part of the annulus. If the amplitude of the bed fluctuations significantly grows, the spouting becomes progressively incoherent.

\section{Results and discussion}

\subsection{Apparatus without draft plates}

In the following the impact of the shape of the central profile and of the prismatic angle $\theta$ will be described and discussed. The main mechanisms causing instabilities in the spouted bed of this 
$0 \mathrm{~m}^{3} / \mathrm{s}$
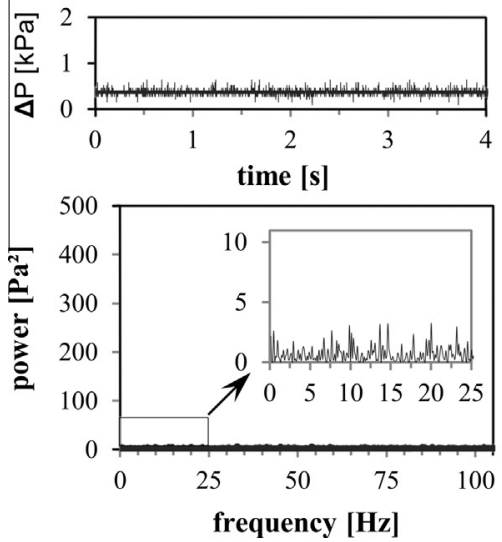

$0.03 \mathrm{~m}^{3} / \mathrm{s}$
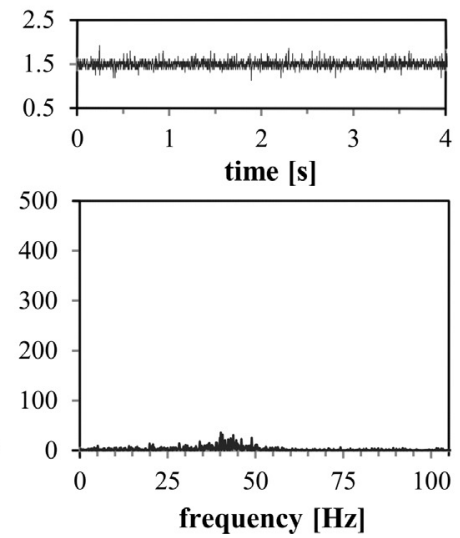

$0.046 \mathrm{~m}^{3} / \mathrm{s}$
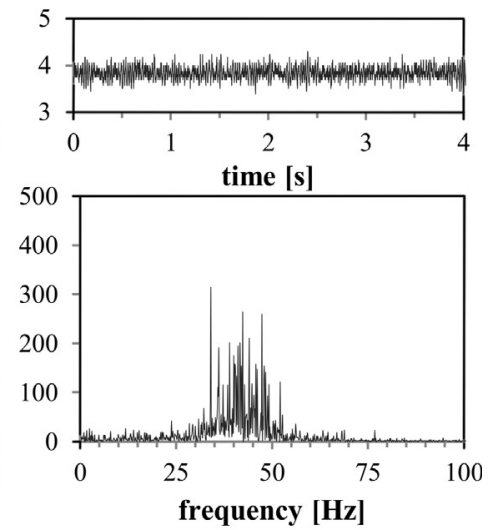

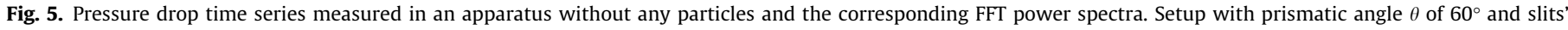
height $h=3 \mathrm{~mm}$.

type were specified in our previous work [11] as (i) the alternating spout deflection with increase in air flow rate and (ii) the bed pulsations (incoherence) due to oscillations in the spout cross-section, which grows with static bed height and inlet size. Therefore, in this work it was particularly intended to observe the influence of undertaken geometrical variations on these effects. The alternating spout deflection can be recognized by a visual observation (Fig. 2) and non-visually by pressure drop signal $[10,11]$. For the incoherent behaviour a strong change in bed expansion (fountain height) in a periodical manner and high amplitude of the pressure drop fluctuations are characteristic.

Gryczka et al. [10] hypothesized that the shape of the central profile can be the reason for the instability growth by the alternating spout deflections and an optimization of the geometry of this profile can lead to a more stable spouting over a larger range of the gas flow rate. Therefore, in this work, we initially evaluated the influence of central profile on flow stability by replacing the "sharp" profile in the apparatus with prismatic angle of $60^{\circ}$ (used by Gryczka et al.) by a "smoothed" one (Fig. 3c). However, according to the visual observation and pressure drop behaviour, this modification of the central profile showed a low influence on the bed behaviour under the condition of an increasing air flow rate. The particle flow patterns shown in Fig. 2 are hardly influenced by the profile and the impact on the spouting stability is negligible. The flow destabilization by alternating spout deflections is neither eliminated nor remarkably reduced. Therefore, further investigations on influence of prismatic angle and draft plates were continued with the original "sharp" geometry of the central profile. This is because the "smoothed" profile geometry is significantly more complex in the production (the profile was eroded from a massive steel block), compared to the "sharp" shape, so that there is no reason for this modification.

The influence of the prismatic angle was investigated both for increasing and decreasing angles. The prismatic angle has a pronounced influence on the particle flow. Regarding the instability mechanisms specified above, an increase of the basis angle facilitates the alternating spout deflection, but reduces the incoherence and vice versa. In apparatuses with prismatic angles higher than $60^{\circ}$ the first and with angles lower than $60^{\circ}$ the second mechanism seem to dominate. The typical visual appearance of the alternating spout deflection can be seen in Fig. 2 for the reference geometry with prismatic angle of $60^{\circ}$ and in Fig. 9a for $80^{\circ}$. In apparatuses with angles of $60^{\circ}$ and $80^{\circ}$ this deflection decreases only slightly with an increase of the static bed height. For reduced prismatic angles of $40^{\circ}$ and $50^{\circ}$ the suppression of the spout deflection by the bed is more pronounced, however the decrease in the angle provokes a significant growth of spouting incoherence. Fig. 6 shows the amplitude of the pressure fluctuations plotted in dependence of the prismatic angle and air flow rate. The amplitude is expressed as standard deviations (STD) of the measured pressure time series. For all prismatic angles, this amplitude grows with the air flow rate, passes through a global maximum and decreases again. This decrease can also be utilized for the determination of an initiation of dilute spouting regime, as proposed in [29] for an entirely conical bed. If one compares the curves measured at different prismatic angles, it is conspicuous, that the amplitude of the pressure drop fluctuations and thus the incoherent flow behaviour increases with decreasing prismatic angle. The highest maximum of pressure drop fluctuations corresponds to the lowest prismatic angle of $40^{\circ}$. The influence of the bed inventory on spouting incoherence is shown in Fig. $6 \mathrm{~b}$ for two prismatic angles $\left(50^{\circ}\right.$ and $80^{\circ}$ ) and inlet size of $3 \mathrm{~mm}$. As ordinate the maxima of the amplitude of pressure drop fluctuations, measured for different bed inventories, are shown. The magnitude of the pressure drop fluctuations is higher for the apparatus with lower prismatic angles of $50^{\circ}$ for all applied bed inventories and grows faster with increasing of the static bed height (bed weight). As shown in our previous DPM study [11], the pressure drop fluctuations in this bed are caused by the oscillations in the spout cross-section. The spout shape in this apparatus is not constant; it changes the shape from a minimum to a maximum cross-section in a periodical manner. In Fig. 7 these oscillations are shown schematically. The necking of the spout takes place in the bottom part of the spout (in the area above the central profile). The spout is partially chocked during such an oscillation which causes a pressure variation. Due to the slanted walls in the prismatic part the annular particles slide under influence of the gravity towards the spout and cause a local deformation of the spout-annulus interface. A possible explanation for higher amplitude of the pressure drop fluctuations and progressively incoherent behaviour is that a decrease of the prismatic angle raises the magnitude of this spout deformation. The particles in the annulus are hardly fluidized, are rather in long time contact than in a colliding state and move downwards as a bulk [11]. The annulus weight loads from one side the apparatus wall and on the other side the gas jet. The instantaneous spout shape is determined by stresses acting in the spout-annulus interface. The resolution of the annulus weight in directions normal and parallel to the slanted wall (towards the spout bottom part) are predetermined by the given prismatic angle. The force component parallel to the slanted wall $F_{\mathrm{p}}=F_{\mathrm{g}} \cos (\theta / 2)$ grows if the included angle of 

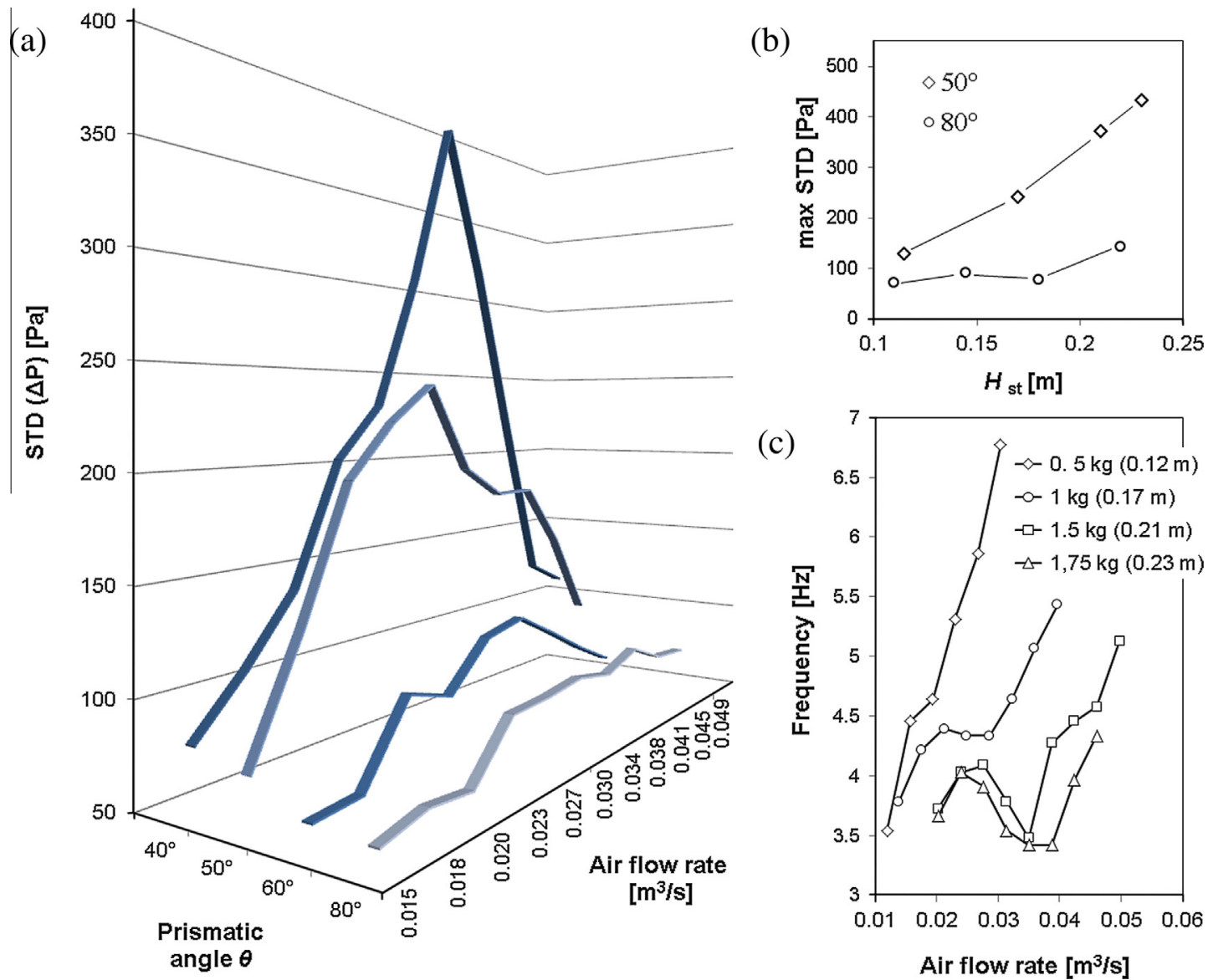

(c)

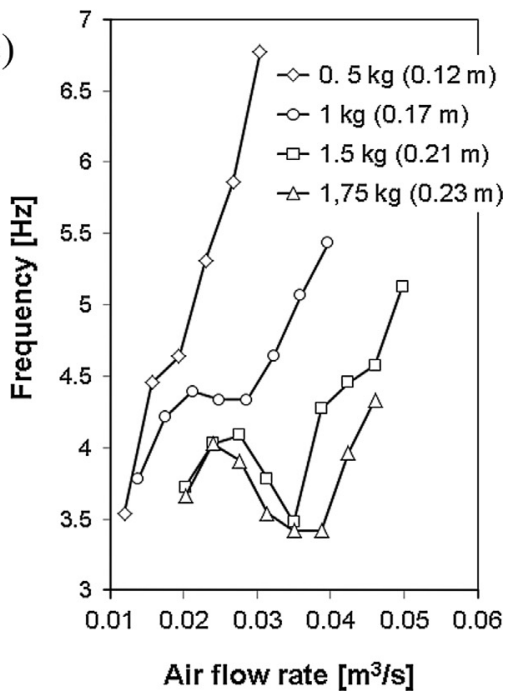

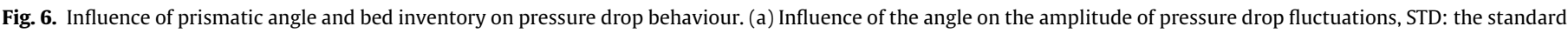

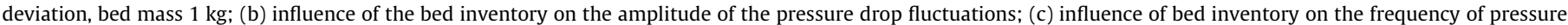
drop fluctuations in apparatus with prismatic angle of $50^{\circ}$. In all three cases polypropylene particles and slits' height of $3 \mathrm{~mm}$ were used.

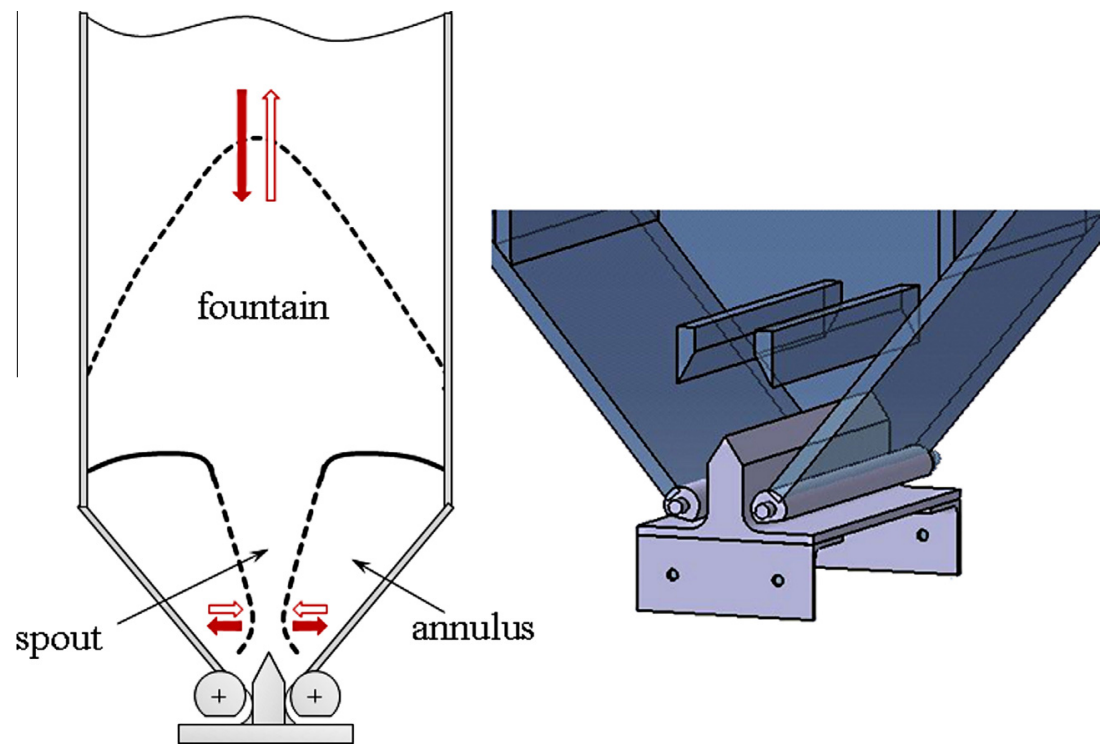

Fig. 7. Schematic representation of incoherent behaviour due to the oscillations of the spout cross-section (based on [11]) and design of bottom draft plates.

the prismatic part is reduced. At reduced prismatic angles, the particles in the annulus achieve a higher velocity and thus momentum. Thus, the load and deformation of the spout-annulus interface grow both with an increase of the annulus weight and a decrease of prismatic angle. The anew straightening of the spoutannulus interface during such an oscillation may occur by release of the necking under shear exerted by the gas jet. The particles entrained during the decollation of these areas are transported upwards as large clusters.

Both effects in a superposition (the angle reduction and increase in the bed mass) can finally cause for low prismatic angles and deeper particle beds a slugging-like behaviour, similar to that 

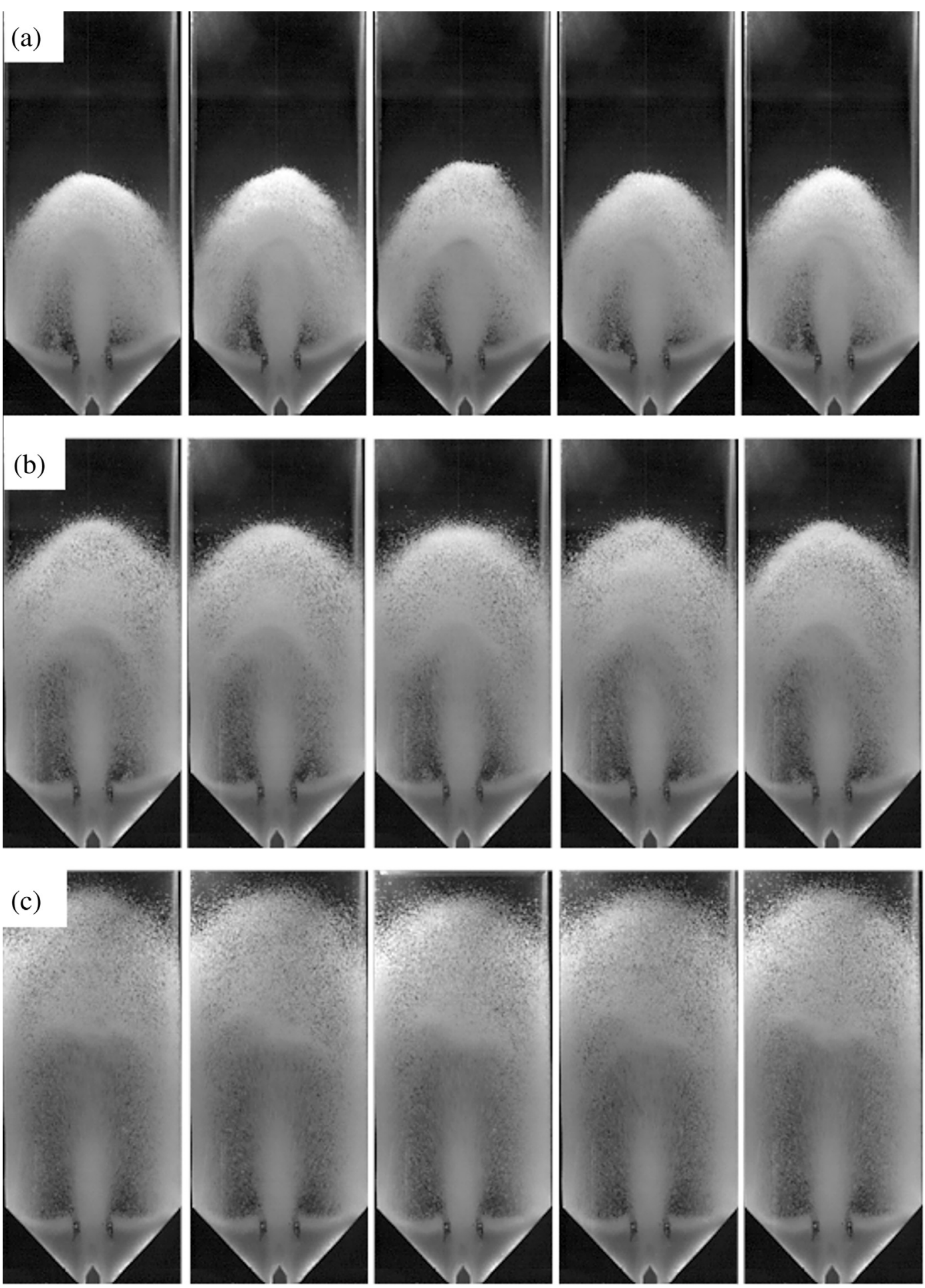

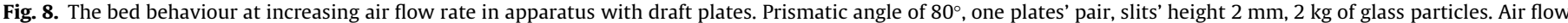
rates: (a) $0.037 \mathrm{~m}^{3} / \mathrm{s}$, (b) $0.041 \mathrm{~m}^{3} / \mathrm{s}$, (c) $0.046 \mathrm{~m}^{3} / \mathrm{s}$. Snapshots were captured with time interval of $0.2 \mathrm{~s}$.

described by Mathur and Epstein [4] for conventional spouted beds. In this regime the entire bed tends to be lifted by the air flow in a periodical manner. This instability is also identifiable nonvisually by means of the pressure drop signal. Fig. 6c shows the main frequencies of the pressure drop fluctuations, obtained from FFT transform, plotted against the air flow rate for different bed inventories. The onset of this slugging-like regime is accompanied not only by very high amplitudes of the gas pressure fluctuations but also by a breakdown in the frequency growth with the air flow rate beginning from a certain "critical" bed inventory (for polypropylene in Fig. $6 \mathrm{c}$ at the bed mass of about $1 \mathrm{~kg}$ ). With increase of the gas flow rate initially the central area of the bed above the inlet becomes loose and a bubbling is initiated "as usual". With further increase in the gas flow rate bubbles arise more frequently. Therefore the frequency of the pressure drop fluctuations produced by bursting of the bubbles on the bed surface grows. However with an increase of the gas flow rate this regime will not turn into the spouting and a further increase of 

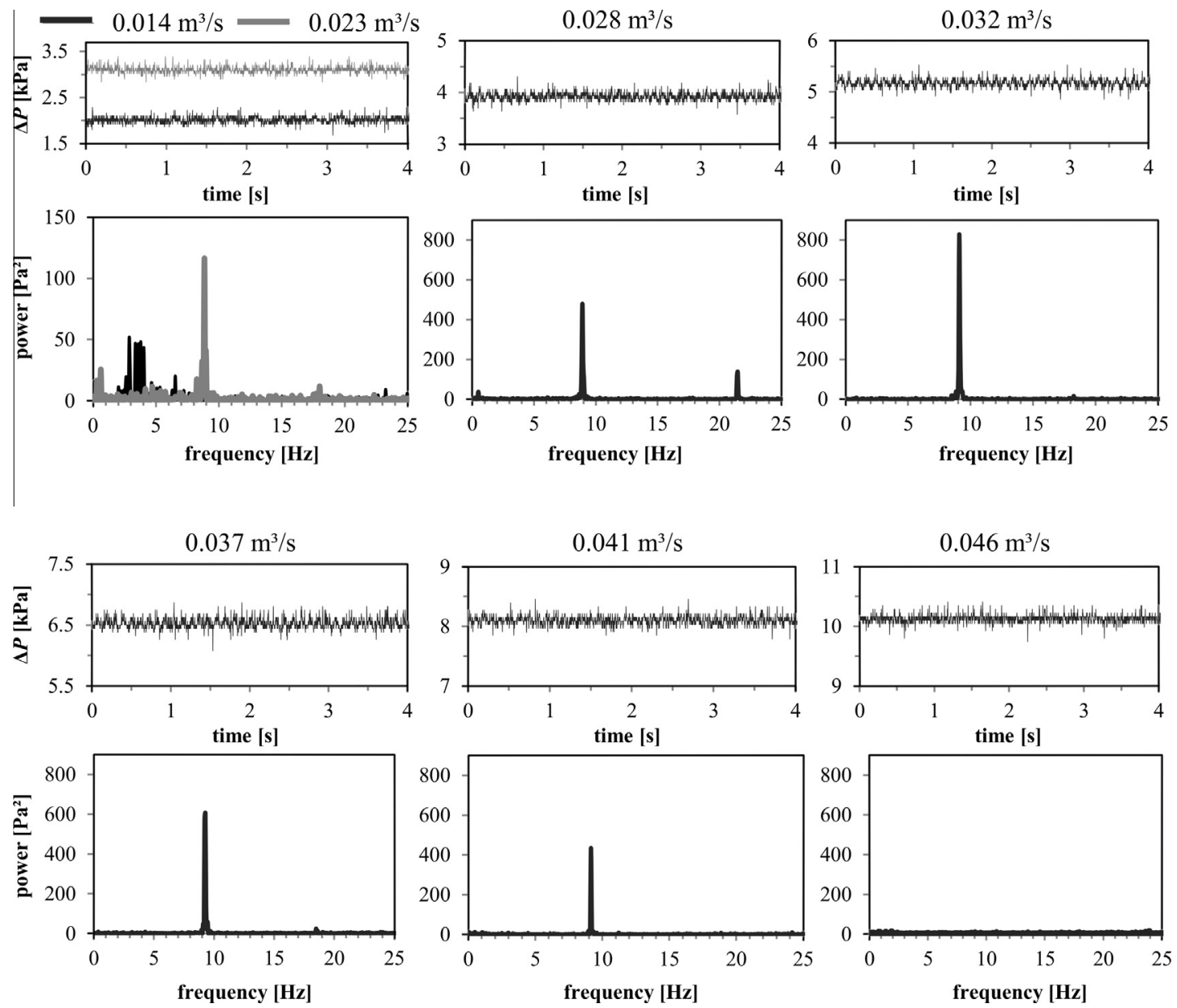

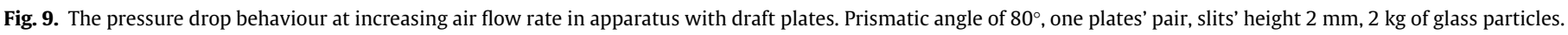

the frequency to $5-6 \mathrm{~Hz}$, but result in a different fluidization mechanism. No continuous spout in the central area of the bed will arise. Probably the onset of the slugging-like behaviour can be correlated with the loosening of the annulus area. With increasing air flow rate the central area of the bed becomes better agitated, but the annulus remains less mobile during the bubbling period. But, at a certain gas velocity also the annulus becomes loose enough to allow for a massive particles' displacement towards the central area. Under conditions of a low prismatic angle (and high enough bed mass) the particle supply from the annulus causes a blockade of the area above the inlet and a redistribution of solids in the overlaying apparatus part. To overcome this state, the blockade itself and the particle layers above should be lifted by gas jet. The entire particle bed behaves thereby like an arc, which arises, expands and erupts in a periodical manner. The lifting of almost the entire particle bed requires a buildup of a significantly higher underpressure and this event takes a longer time than an oscillation in the spout diameter; therefore the amplitude of the pressure drop fluctuations is higher and the fluctuations' frequency lower.

Nevertheless, a reduction of the cone/prismatic angle can bring some advantages for the application. A reduced angle provokes a lower reduction of gas velocity within the prismatic part, as well as provides for a steeper annulus with a faster downwards particle motion. The spouting becomes more intense (vigorous) and a formation of dead zones is less probable. Additionally, in the apparatus with a small angle more particles reside in the spraying zone. Therefore apparatuses with a small angle should be preferable for applications requiring high particle translational and angular velocities as well as circulation rates, e.g. such as coating.
For instance, Publio and Oliveira [30] experimentally found out that for a conventional spouted bed both the growth rate and quality of the coating layers increase when the cone angle is reduced from $60^{\circ}$ to $40^{\circ}$. Salikov et al. [13] compared the particle dynamics in a prismatic apparatus for the same angles by means of DPM simulations of a shallow particle bed. A significantly broader distribution of the particle velocity and higher particle rotation was found for the reduced angle. However, the spouting stability was found to be significantly affected. As shown above for deeper beds, the spouting in the apparatus with low prismatic angle is less stable due to a reduced coherence and a pronounced disposition to the slugging-like behaviour. Whereas, in the apparatus with an angle of $40^{\circ}$ the slugging occurs already at relatively low static bed heights. Moreover, in this configuration at elevated air flow rates spout often adheres to one of the side walls in a permanent manner. Therefore, decreasing the prismatic angle until $40^{\circ}$ does not seem to be reasonable, particularly if the apparatus should be used with substantial bed masses; we suggest this is the lowest limit for this apparatus type. This value is also in agreement with a cone angle of $40^{\circ}$ specified by Mathur and Epstein [4] for conventional spouted bed and higher than the limiting value of $28^{\circ}$ for entirely conical apparatuses specified by Olazar et al. [31]. However, the prismatic angle of $50^{\circ}$ is indeed an interesting compromise between the spouting intensity and stability, and an investigation worth for future comparative DPM and coating studies on this apparatus. The reduced disposition to the alternating spout deflection of apparatuses with reduced prismatic angle is advantageous and the increased level of the incoherence is however detrimental. 

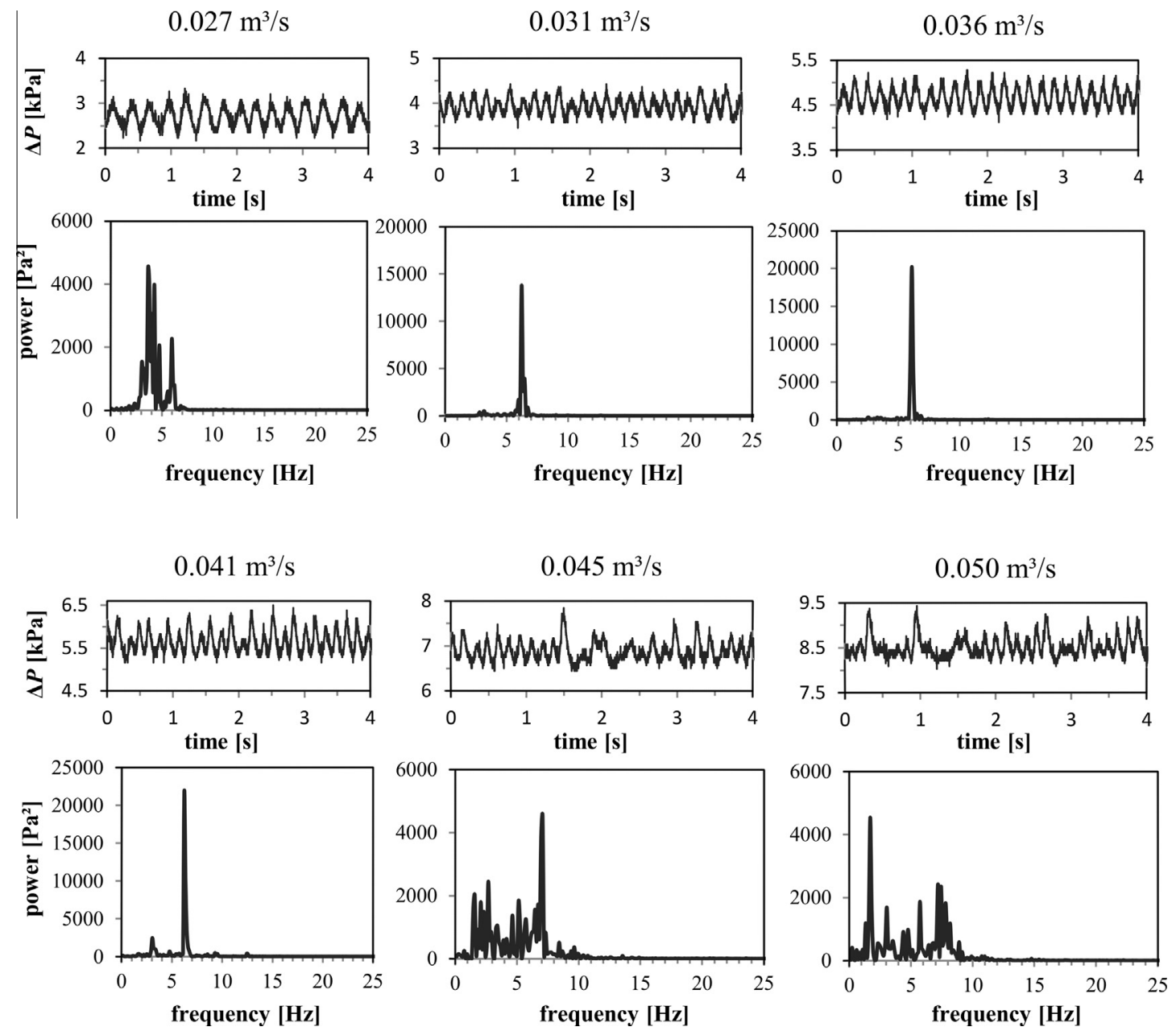

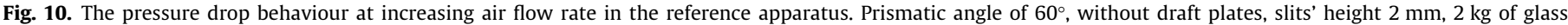
particles.

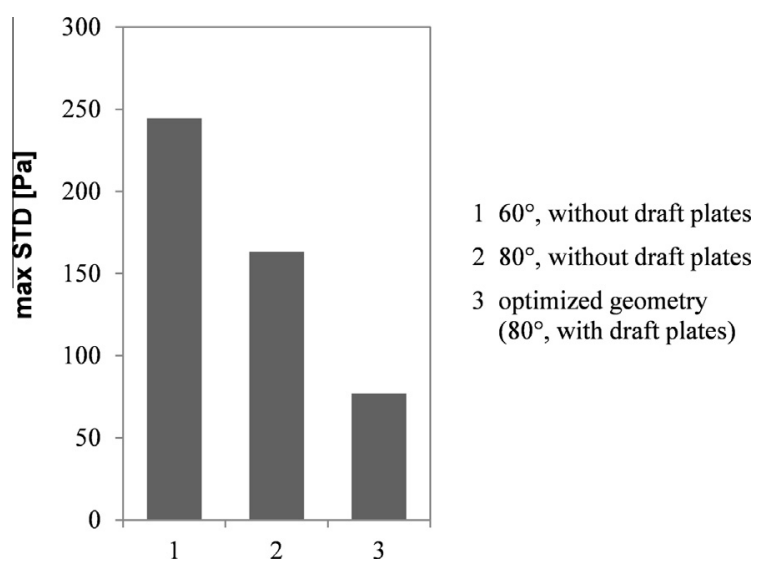

Fig. 11. Comparison of the maximum amplitude (STD) of the pressure drop fluctuations for different configurations of prismatic spouted beds. Slits of $2 \mathrm{~mm}$ height and the bed of $2 \mathrm{~kg}$ of glass particles are used in each case.

\subsection{Draft plates}

This section describes a method to make the spouting in this apparatus especially stable and the spouting stability virtually independent on the gas velocity. As described above, all stability issues could not be encountered by a manipulation with prismatic angle. Therefore, different configurations of draft plates were applied in attempt to fix both the alternating spout deflection and the spouting incoherence, simultaneously. According to our previous DPM work [11], the area above the central profile seems to be of the highest interest, because this is the place where the incoherence originates from. In this zone both particle flows initiated at gas inlets merge to one spout. Simultaneously, the oscillations in the spout cross-section occur here. To suppress these oscillations small drafts plates (height of $30 \mathrm{~mm}$ ) slanted towards the spout inner were applied (Fig. 7 right). The plates focus the spout and constrain it to the approximately minimal cross-section of an oscillation. The effect of the plates on the particle flow profile is shown in Fig. 8 for the apparatus filled with $2 \mathrm{~kg}$ of glass particles. The achieved spouting fulfills very well stability criteria proposed by Chen [15]: the particle flow is steady-state, smooth and symmetrical. Both instability effects namely the alternation spout deflection and the incoherence are suppressed. The height of the fountain remains nearly constant with time. This stability is widely independent on the gas velocity; the increase in the gas flow rate results only in a growing fountain height, without disturbing the uniform particles' circulation. Fig. 9 shows the evolution of the pressure drop fluctuations for the apparatus configuration, shown in Fig. 8, in contrast to the reference geometry, filled with the same amount of glass particles (Fig. 10). The evolution of the pressure behaviour with the air flow rate is different for both geometries. The trend in Fig. 10 resembles well the typical behaviour of the reference apparatus, shown exemplarily in Fig. 4a and described in more detail in $[10,11]$. The regular pressure 

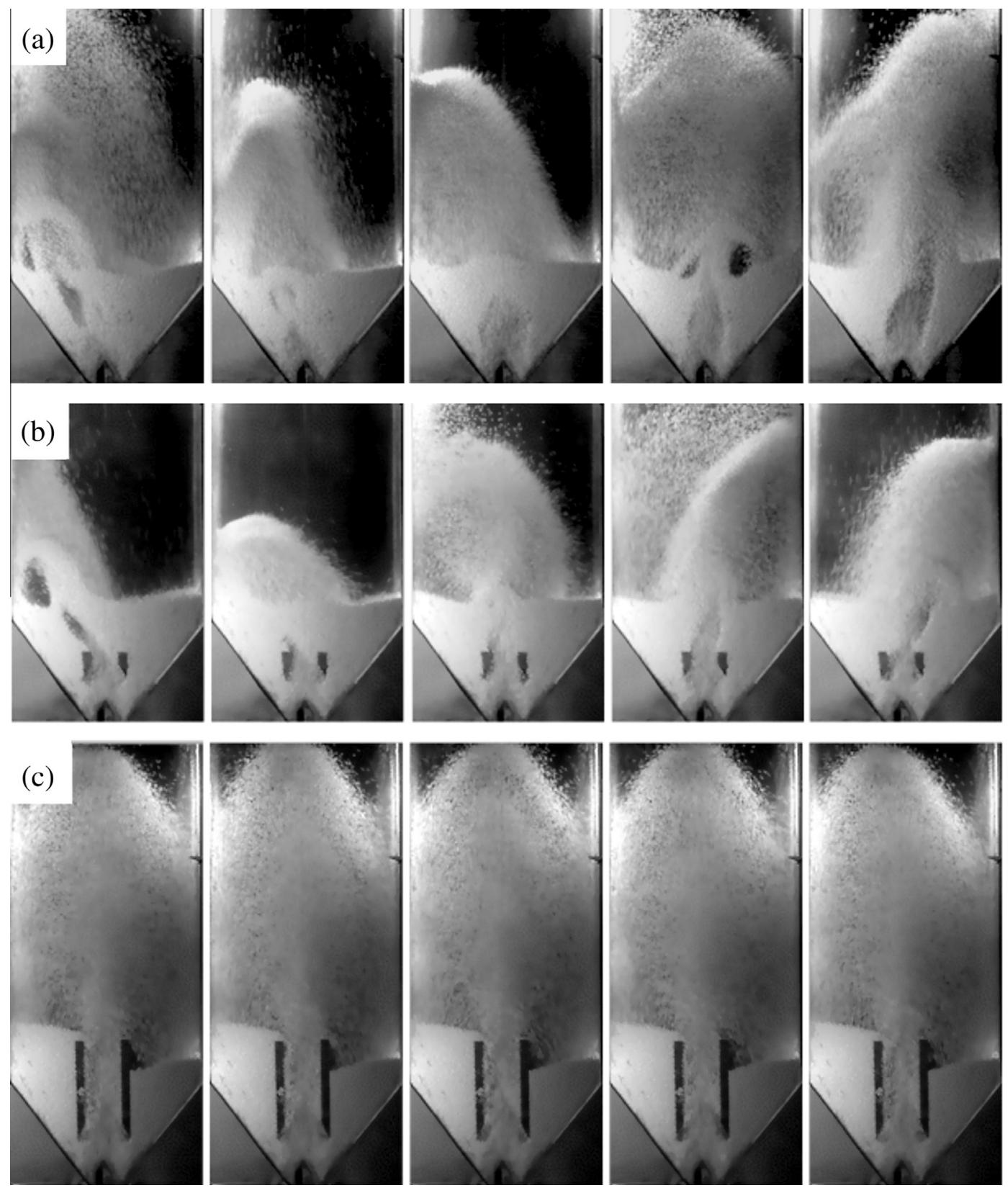

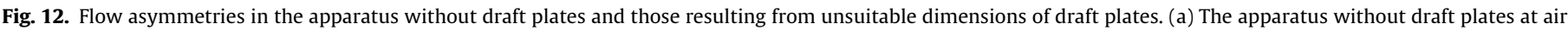

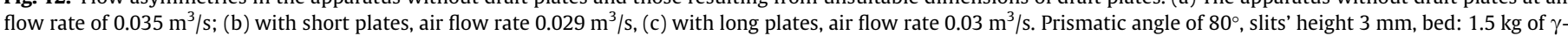
$\mathrm{Al}_{2} \mathrm{O}_{3}$ particles with $d_{50}=1.77 \mathrm{~mm}$; snapshots were captured with time interval of $0.2 \mathrm{~s}$.

drop behaviour is consistent only over a limited range of the air flow rate, after this a flow destabilization takes place. Single narrow peaks in the frequency domain, specified by Gryczka et al. [10], as an attribute of the initiation of stable spouting, can be found at air flow rate of $\sim 0.03 \mathrm{~m}^{3} / \mathrm{s}$ for the first time. The appearance of an additional peak in the frequency domain can be seen in the power plot corresponding to the gas flow rate of $0.041 \mathrm{~m}^{3} / \mathrm{s}$. The non-uniformity of the fluctuations can also be directly observed in the captured pressure drop signal. With further increase in the air flow rate this irregularity grows and results in a high scatter of detected frequencies. The pressure drop behaviour of the optimized geometry is different. The frequency of the initiated spouting is higher $(\sim 9 \mathrm{~Hz}$ compared to $\sim 6 \mathrm{~Hz}$ in the reference case) and the increase of the air flow rate does not lead to the irregularities in the pressure drop signal. The pressure data in the bottom sequence in Fig. 9 corresponds to the particle flow patterns shown in Fig. 8. The pressure continues to fluctuate uniformly at the air flow rates of 0.037 and $0.041 \mathrm{~m}^{3} / \mathrm{s}$ (states a and $b$ in Fig. 8). The flow at the highest of the shown gas velocities $\left(0.046 \mathrm{~m}^{3} / \mathrm{s}\right)$ produces however no pronounced peaks in the frequency domain. The measured pressure signal and FFT power plot in the relevant range of $0-25 \mathrm{~Hz}$ are comparable with the sensor noise (Fig. 5). This behaviour is typical for a stable dilute spouting regime [11], although a high amount of particles in the apparatus is still in the dense state in the shown case (Fig. 8c). The reason for this behaviour should be however the same as for the dilute spouting; this implies that no flow mechanism is present which can cause significant pressure fluctuations, like oscillations in the spout cross-section or a bursting of bubbles. The entrainment of particles by the spout from the annulus area and the particle circulation in the apparatus are very uniform and steady-state. At lower gas flow rates, i.e. in the range where periodical pressure drop fluctuations 

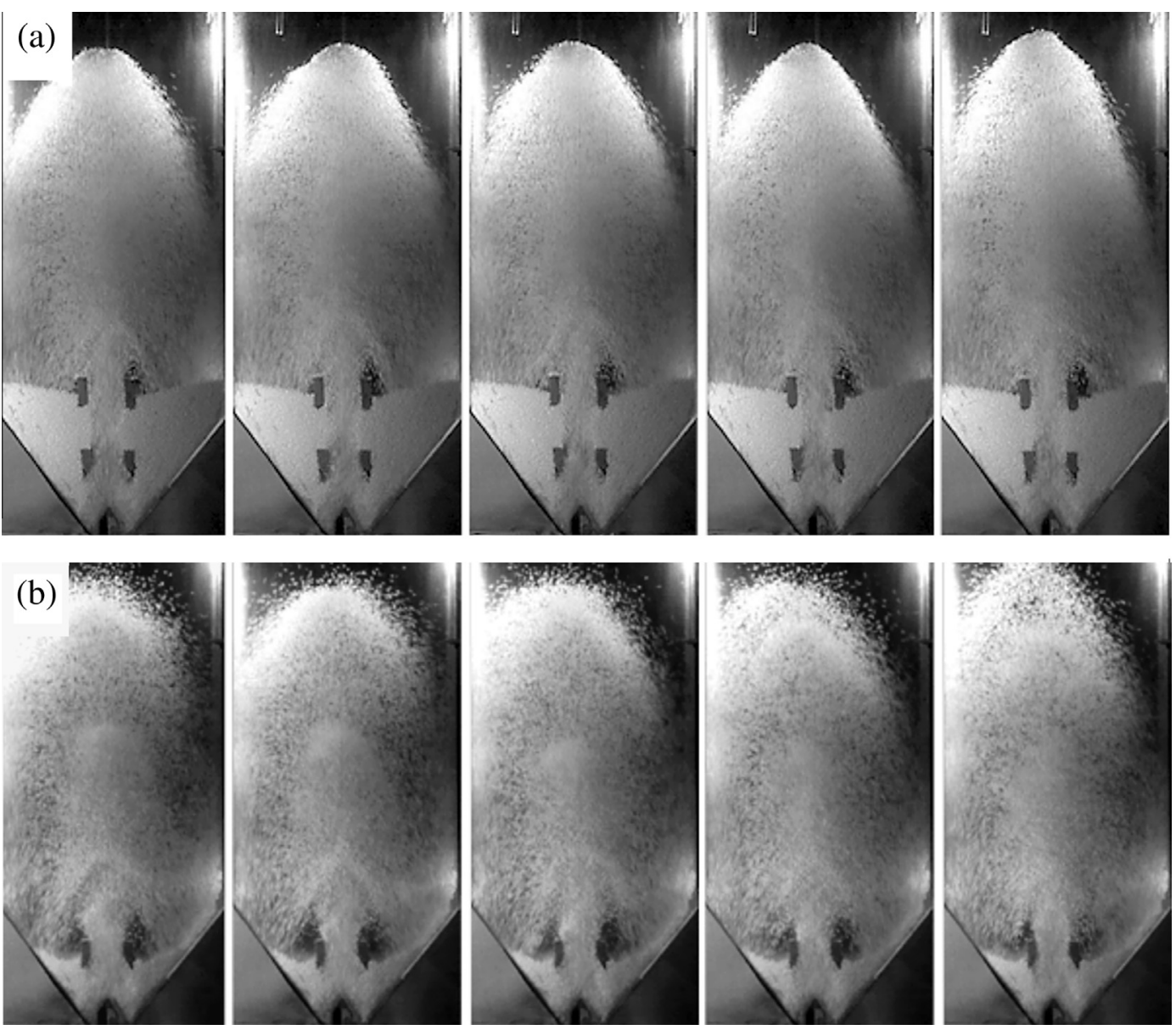

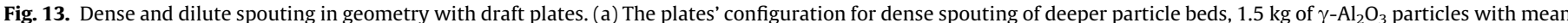

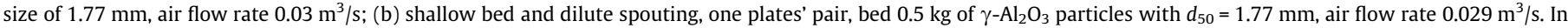
both cases prismatic angle of $80^{\circ}$ and slits' height of $3 \mathrm{~mm}$ were used. Snapshots were captured with time interval of $0.2 \mathrm{~s}$.

are present, these have small amplitudes. Fig. 11 shows a comparison of the maxima of the amplitude of pressure drop fluctuations for the reference $\left(60^{\circ}\right.$, without plates) and optimized $\left(80^{\circ}\right.$, with plates) geometries, as well as for a geometry with a prismatic angle of $80^{\circ}$ and without draft plates. The geometry with a prismatic angle of $80^{\circ}$ has the lowest amplitude of the pressure drop fluctuations from all geometries without draft plates (Fig. 6a), i.e. the highest prismatic angle ensures the most coherent behaviour in the investigated range. The insertion of draft plates in this configuration allows for further improvement of this parameter. However, it should be noted that the high prismatic angle of $80^{\circ}$ is yet sufficient to provide for a throughout circulation without a formation of dead zones in the annulus for used Geldart D and B particles, but can lead to this issue in case of finer ones.

Investigations with increasing and decreasing static bed height in the geometry with draft plates showed that this configuration only performs well for static bed heights, which did not significantly differ from the height of the upper edges of the draft plates. In general, the best stability is achieved if the static bed is at the same level or slightly below. For static bed heights significantly higher than the plates' upper edges the alternating spout deflection appears again as shown in Fig. 12b (compare with the behaviour, shown in Fig. 12a for the apparatus with the same prismatic angle but without draft plates). The adjustment of the plates' height (Fig. 12c) on the static bed height in fact solved this issue, but a different instability arises, namely an unsymmetrical solids' distribution in the annulus sections. This kind of instability was also reported for the slot-rectangular spouted bed with one vertical gas inlet by Luo et al. [23] and a rectangular spout-fluidized bed by Sutkar et al. [32]. The bed asymmetry increases, if the static bed height is reduced again and the static height becomes smaller than the height of the draft plates. This issue could be encountered by means of a configuration using two pairs of plates (Fig. 13a). This spouted bed can be regarded as a kind of rectangular analogue to the open-sided tubes used by Altzibar et al. [18,19] for entirely conical spouted beds. This configuration provides for enlarged interaction areas between spout and annulus compartments and additional pathways for the particle circulation. The spouting of deeper beds achieved with two pairs of draft plates is very uniform and the stability is also highly independent on the gas velocity, however if the top pair of plates is correctly positioned. Some simple practical recommendations for this positioning can be given as:

(i) The vertical position should be adjusted on the static bed height; upper edges of top plates should approximately level the static bed height (or vice versa).

(ii) After leaving the area between bottom plates the spout has a slightly diverging shape. Therefore, if deeper particle beds should be used, the horizontal distance between the top plates have to be slightly enlarged to fit the spout.

Therefore, for laboratory plants, which are usually used for experiments with different particles and bed inventories, the position of the upper pair of draft plates should be made adjustable. E.g. for our setup we realized this by means of strong magnets implanted into the top plates, to allow the plates' replacement 

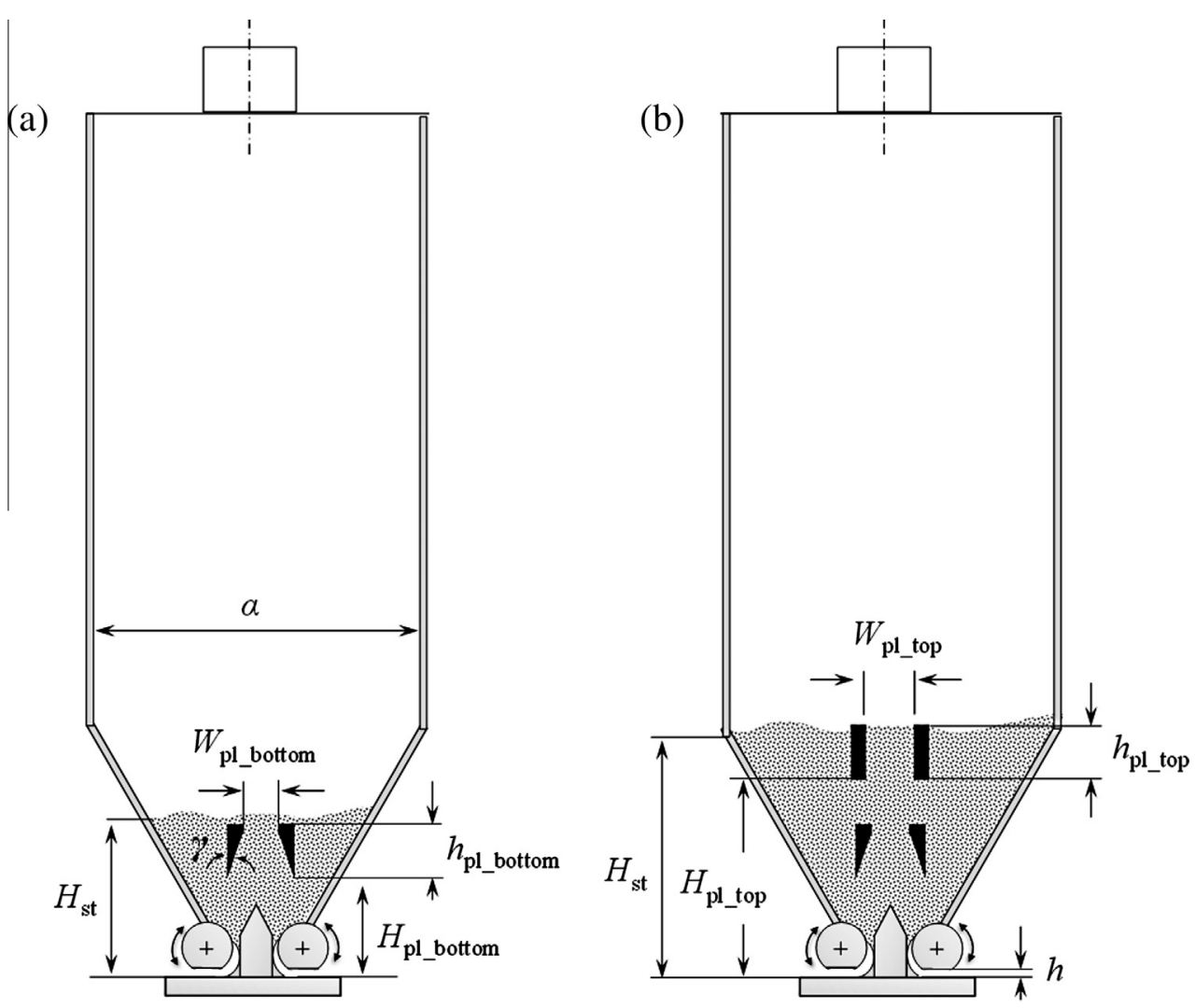

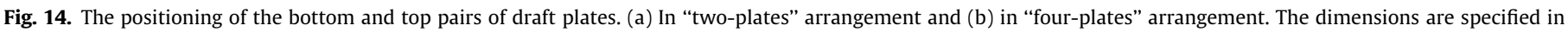
Tables 2 and 3.

Table 2

Fixed dimensions of optimized apparatus geometry.

\begin{tabular}{llllll}
\hline Dimension & $\begin{array}{l}H_{\text {pl_bottom }} \\
(\mathrm{mm})\end{array}$ & $\begin{array}{l}W_{\text {pl_bottom }} \\
(\mathrm{mm})\end{array}$ & $\begin{array}{l}h_{\text {pl_bottom }} \\
(\mathrm{mm})\end{array}$ & $\begin{array}{l}h_{\text {pl_top }} \\
(\mathrm{mm})\end{array}$ & $\begin{array}{l}\gamma \\
\left({ }^{\circ}\right)\end{array}$ \\
\hline Value & 80 & 34 & 30 & 30 & 30 \\
\hline
\end{tabular}

from outside. The details to the positions and shape of the bottom plates can be found in Fig. 14a and Table 2. These positions are optimal regarding the flow stability; at least for all particles used in this work, which means that the particle flow patterns were constant over time and the spout coherent. For shallow beds the top pair of the plates is redundant. The optimal positions of top plates for solids and bed inventories used in this work are given in Fig. 14b and Table 3. The apparatus with included prismatic angle of $80^{\circ}$ in combination with draft plates provides the most stable regime. Contrary to the reference apparatus, in the geometry equipped with draft plates the static bed height is permitted to exceed the height of the prismatic region (Fig. 13a). However, if vertical distances between the bottom and the top pairs of plates become high (for high static beds), an additional periodical oscillation of the spout in the areas between the top and bottom pairs of plates arises. For very shallow static beds a stable dilute spouting was also observed in the apparatus equipped with draft plates. The corresponding particle flow patterns are shown in Fig. 13b.

\subsection{Geldart B particles}

Traditionally, spouted beds are applied for large particles (Geldart D). Nevertheless, there are several reports for application of spouted beds for fine and light particles by means of dilute spouting regime, e.g. $[1,2]$. However, a practical application of this regime is limited to quite shallow particle beds. Furthermore, large apparatuses are required for dilute spouting of fine particles. The investigations on dilute spouting of particles finer and lighter than Geldart B were not covered in this work due to insufficient freeboard height of the experimental setup, as well as deeper beds of Geldart B particles with "four-plates" arrangement. The adjustable apparatus was not designed high enough from the standpoint of limited mechanical stability at underpressure conditions. Geldart B particles used in this work (Table 1 ) showed indeed a very small interval of the stable (dense) spouting, irrespective of the used prismatic angle. The spout was quite discontinuous (rather similar to an area with small ascending bubbles in the central region of the apparatus), which results in broader peaks in the FFT power plots. A rather continuous spout and more extended interval of the dense spouting could be found only in apparatus with the highest of the investigated prismatic angle $\left(80^{\circ}\right)$. The draft plates also improved the apparatus performance for finer particles, which is also in accordance with behaviour of conventional axisymmetric beds equipped with draft tubes $[17,18]$. Fig. 15 shows transition lines between regimes obtained for apparatus with and without draft plates for Geldart B particles used in this work, in a comparison. The area of the stable (dense) spouting is enlarged.

\section{Conclusions}

This paper presents an investigation especially on spouting stability on a slot-rectangular (prismatic) spouted bed with two adjustable gas inlets, which is widely used in the industry. On the basis of this study an optimization of the apparatus with regard to improvement of the spouting stability of large particles is proposed. The study comprehended the investigations on the effect of the shape of the central profile, the angle of the prismatic 
Table 3

Positioning of top draft plates in apparatus with prismatic angle of $80^{\circ}$.

\begin{tabular}{|c|c|c|c|c|}
\hline Particles & $\begin{array}{l}\text { Bed mass } \\
(\mathrm{kg})\end{array}$ & $\begin{array}{l}\text { Pairs of } \\
\text { plates }\end{array}$ & $\begin{array}{l}H_{\text {pl_top }} \\
(\mathrm{mm})\end{array}$ & $\begin{array}{l}W_{\text {pl_top }} \\
(\mathrm{mm})\end{array}$ \\
\hline \multirow[t]{8}{*}{ Glass, $d_{\mathrm{p}} \sim 1.57 \mathrm{~mm}$} & 0.5 & Bottom $^{a}$ & - & - \\
\hline & 0.75 & Bottom & - & - \\
\hline & 1.0 & Bottom & - & - \\
\hline & 2.0 & Bottom & - & - \\
\hline & 3.0 & $\begin{array}{l}\text { Bottom and } \\
\text { top }\end{array}$ & 140 & 34 \\
\hline & 4.0 & $\begin{array}{l}\text { Bottom and } \\
\text { top }\end{array}$ & 165 & 34 \\
\hline & 5.0 & $\begin{array}{l}\text { Bottom and } \\
\text { top }\end{array}$ & 198 & 40 \\
\hline & 6.0 & $\begin{array}{l}\text { Bottom and } \\
\text { top }\end{array}$ & 216 & 40 \\
\hline \multirow[t]{6}{*}{$\gamma-\mathrm{A}_{2} \mathrm{O}_{3}, d_{\mathrm{p}} \sim 1.77 \mathrm{~mm}$} & 0.5 & Bottom & - & - \\
\hline & 0.75 & Bottom & - & - \\
\hline & 1.0 & $\begin{array}{l}\text { Bottom and } \\
\text { top }\end{array}$ & 135 & 34 \\
\hline & 1.5 & $\begin{array}{l}\text { Bottom and } \\
\text { top }\end{array}$ & 160 & 34 \\
\hline & 2.0 & $\begin{array}{l}\text { Bottom and } \\
\text { top }\end{array}$ & 170 & 34 \\
\hline & 2.5 & $\begin{array}{l}\text { Bottom and } \\
\text { top }\end{array}$ & 230 & 50 \\
\hline \multirow{7}{*}{$\begin{array}{l}\text { Polypropylene } \\
d_{\mathrm{p}} \sim 4.4 \mathrm{~mm}\end{array}$} & 0.25 & Bottom & - & - \\
\hline & 0.5 & Bottom & - & - \\
\hline & 0.75 & Bottom & - & - \\
\hline & 1.0 & Bottom & - & - \\
\hline & 1.5 & $\begin{array}{l}\text { Bottom and } \\
\text { top }\end{array}$ & 160 & 34 \\
\hline & 2 & $\begin{array}{l}\text { Bottom and } \\
\text { top }\end{array}$ & 200 & 40 \\
\hline & 2.5 & $\begin{array}{l}\text { Bottom and } \\
\text { top }\end{array}$ & 240 & 50 \\
\hline \multirow[t]{6}{*}{$\gamma-\mathrm{A}_{2} \mathrm{O}_{3}, d_{\mathrm{p}} \sim 0.65 \mathrm{~mm}$} & 0.5 & Bottom & - & - \\
\hline & 0.75 & Bottom & - & - \\
\hline & 1.0 & Bottom & - & - \\
\hline & 1.5 & Bottom & - & - \\
\hline & 2 & Bottom & - & - \\
\hline & 2.5 & Bottom & - & - \\
\hline
\end{tabular}

a The positions of the bottom plates are the same for all shown cases $\left(H_{\text {pl_bottom }}\right.$ and $W_{\text {pl_bottom }}$ in Table 2 ). apparatus region and draft plates. For determination of the stability the evaluation of the pressure drop behaviour and visual observations of the particle flow patterns were applied. As stability criteria the flow symmetry, repeatability of the particle flow patterns over time, as well as the uniformity and amplitude of the pressure drop fluctuations were used. In the reference geometry the main sources of instability are the alternating spout deflections and spout incoherence. The first mechanism is responsible for the flow destabilisation with gas velocity beyond a certain value. The spout incoherence increases with static bed height. When the smoothing of the shape of the central profile showed a negligible influence, the prismatic angle was found to have a significant effect on the flow stability. Regarding both apparatus-specific instability mechanisms (alternating spout deflections and incoherence), the increase of the basis angle facilitates the alternating spout deflection, but reduces the spouting incoherence and vice versa. In apparatuses with prismatic angles higher than $60^{\circ}$ the first and with the angle lower than $60^{\circ}$ the second mechanism seem to dominate. In geometries with a low prismatic angle an increase of the static bed height beyond a certain value can lead to a slugging-like behaviour. Thus, both instability issues cannot be simultaneously minimized alone by the manipulations with prismatic angle.

A further tested modification was the introduction of draft plates. A design of draft plates is presented, which provides for significantly improved quality of particle flow. Concerning the spouting stability, the best found configuration was the apparatus with the included prismatic angle of $80^{\circ}$ equipped with draft plates. The achieved stability is highly independent on the gas velocity. In the correspondingly designed apparatus, the spouting of Geldart B particles is improved. For shallow beds of large particles (Geldart D) a highly coherent dense spouting regime passes continuously into the stable dilute-like spouting, without stability loss at intermediate gas velocities, characteristic for the reference and any other investigated geometry. The symmetry of the bed material distribution in the annulus depends on the relation between the length of draft plates and static bed height. The static bed height should be levelled on the upper edge of draft plates. To achieve a symmetrical distribution of solids in the annulus area in case of deeper beds, the apparatus should be equipped with
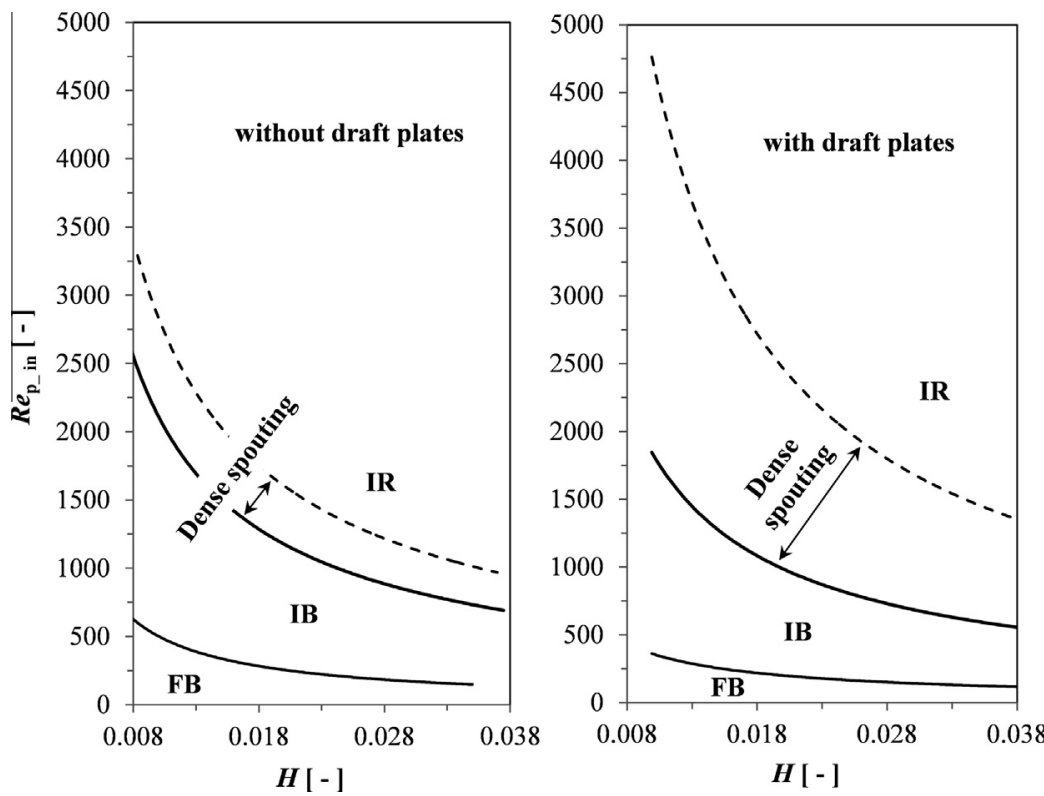

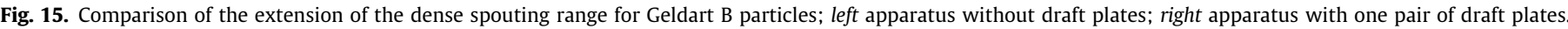
Prismatic angle of $80^{\circ}, \gamma-\mathrm{Al}_{2} \mathrm{O}_{3}$-particles with mean size of $0.65 \mathrm{~mm}$, FB: fixed bed, IB: irregular bubbling, IR: instable region. 
open-sided plates (two pairs of plates). The positioning of the top pair of plates is individual for different static bed heights and particle properties.

\section{Acknowledgements}

We gratefully acknowledge for the financial support: Deutsche Forschungsgemeinschaft (DFG), Germany and Technology Foundation STW, The Netherlands. Project number HE 4526/5.

\section{References}

[1] K. Brandt, M.F.H. Wolff, V. Salikov, S. Heinrich, G.A. Schneider, A novel method for a multi-level hierarchical composite with brick-and-mortar structure, Sci. Rep. 3 (2013) 2322.

[2] M.F.H. Wolff, V. Salikov, S. Antonyuk, S. Heinrich, G.A. Schneider, Novel, highlyfilled ceramic-polymer composites synthesized by a spouted bed spray granulation process, Compos. Sci. Technol. 90 (2014) 154-159.

[3] N. Epstein, J.R. Grace, Spouted and Spout-Fluid Beds: Fundamentals and Applications, Cambridge University Press, Cambridge, 2011.

[4] K.B. Mathur, N. Epstein, Spouted Beds, Academic Press Inc., New York, 1974

[5] L. Mörl, G. Krüger, S. Heinrich, M. Ihlow, E. Jordanova, Steuerbare Gasanströmeinrichtung für Strahlschichtapparate (German patent) 10004939 (2001) 7.

[6] Glatt GmbH, ProCell spouted bed technology, <http://www.glatt.com/en/ products/spouted-bed-systems/, 2014 (accessed 09.01.14).

[7] M. Alnaif, S. Antonyuk, C.M. Hentzschel, C.S. Leopold, S. Heinrich, I. Smirnova, A novel process for coating of silica aerogel microspheres for controlled drug release applications, Microporous Mesoporous Mater. 160 (2012) 167-173.

[8] A. Markowski, W. Kaminski, Hydrodynamic characteristics of jet-spouted beds, Can. J. Chem. Eng. 61 (1983) 377-381.

[9] S.C.S. Rocha, O.P. Taranto, Granulation and particle coating, in: N. Epstein, J.R. Grace (Eds.), Spouted and Spout-fluid Beds: Fundamentals and Applications, Cambridge University Press, Cambridge, 2011, pp. 222-237.

[10] O. Gryczka, S. Heinrich, V. Miteva, N.G. Deen, J.A.M. Kuipers, M. Jacob, L. Mörl, Characterization of the pneumatic behavior of a novel spouted bed apparatus with two adjustable gas inlets, Chem. Eng. Sci. 63 (2008) 791-814.

[11] V. Salikov, S. Antonyuk, S. Heinrich, V.S. Sutkar, N.G. Deen, J.A.M. Kuipers, Characterization and CFD-DEM modelling of a prismatic spouted bed, Powder Technol. 270 (2015) 622-636.

[12] G. Mohs, O. Gryczka, S. Heinrich, L. Mörl, Magnetic monitoring of a single particle in a prismatic spouted bed, Chem. Eng. Sci. 64 (2009) 4811-4825.

[13] V. Salikov, S. Antonyuk, S. Heinrich, Using DPM on the way to tailored prismatic spouted beds, Chem. Ing. Tech. 84 (2012) 388-394.

[14] L.A.P. Freitas, O.M. Dogan, C.J. Lim, J.R. Grace, B. Luo, Hydrodynamics and stability of slot-rectangular spouted beds part II: increasing bed thickness, Chem. Eng. Commun. 181 (2000) 243-258.
[15] Z. Chen, Hydrodynamics, stability and scale-up of slot-rectangular spouted beds, PHD thesis, The University of British Columbia, Vancouver, 2008.

[16] H. Altzibar, G. Lopez, J. Bilbao, M. Olazar, Minimum spouting velocity of conical spouted beds equipped with draft tubes of different configuration, Ind. Eng. Chem. Res. 52 (2013) 2995-3006.

[17] H. Hattori, K. Takeda, Side-outlet spouted bed with inner draft-tube for smallsized solid particles, J. Chem. Eng. Jpn. 11 (1978) 125-129.

[18] H. Altzibar, G. Lopez, S. Alvarez, M.J. San Jose, A. Barona, M. Olazar, A draft-tube conical spouted bed for drying fine particles, Drying Technol. 26 (2008) 308314.

[19] H. Altzibar, G. Lopez, R. Aguado, S. Alvarez, M.J. San Jose, M. Olazar, Hydrodynamics of conical spouted beds using different types of internal devices, Chem. Eng. Technol. 32 (2009) 463-469.

[20] M.I. Kalwar, G.S.V. Raghavan, A.S. Mujumdar, M.A. Fanous, Aerodynamics of grain in a large scale two-dimensional spouted bed with draft plates, in: A.S. Mujumdar, M. Roques (Eds.), Drying'89, Hemisphere, Washington, 1989, pp. 433-439.

[21] M.I. Kalwar, G.S.V. Raghavan, A.S. Mujumdar, Spouting of two-dimensional beds with draft plates, Can. J. Chem. Eng. 70 (1992) 887-894.

[22] M.I. Kalwar, G.S.V. Raghavan, A.S. Mujumdar, Circulation of particles in twodimensional spouted beds with draft plates, Powder Technol. 77 (1993) 233242.

[23] B. Luo, C.J. Lim, L.A.P. Freitas, J.R. Grace, Flow characteristics in slot-rectangular spouted beds with draft plates, Can. J. Chem. Eng. 82 (2004) 83-88.

[24] Z.B. Grbavcic, H. Littman, M.H. Morgan III, J.D. Paccione, Spouted and spoutfluid beds with draft tubes, in: N. Epstein, J.R. Grace (Eds.), Spouted and Spoutfluid Beds: Fundamentals and Applications, Cambridge University Press, Cambridge, 2011, pp. 128-140.

[25] D. Geldart, Types of fluidization, Powder Technol. 7 (1973) 285-292.

[26] L.A.P. Freitas, O.M. Dogan, C.J. Lim, J.R. Grace, D. Bai, Identification of flow regimes in slot-rectangular spouted beds using pressure fluctuations, Can. J. Chem. Eng. 82 (2004) 60-73.

[27] E. Piskova, L. Mörl, Characterization of spouted bed regimes using pressure fluctuation signals, Chem. Eng. Sci. 63 (2008) 2307-2316.

[28] O.M. Dogan, L.A.P. Freitas, C.J. Lim, J.R. Grace, B. Luo, Hydrodynamics and stability of slot-rectangular spouted beds. Part I: thin bed, Chem. Eng. Commun. 181 (2000) 225-242.

[29] L. Leu, R.-S. Pan, Pressure fluctuations in jet spouted beds, Can. J. Chem. Eng. 82 (2004) 1044-1047.

[30] M.C.P. Publio, W.P. Oliveira, Effect of the equipment configuration and operating conditions on process performance and on physical characteristics of the product during coating in spouted bed, Can. J. Chem. Eng. 82 (2004) $122-133$.

[31] M. Olazar, M.J. San Jose, J. Bilbao, Conical spouted beds, in: N. Epstein, J.R. Grace (Eds.), Spouted and Spout-fluid Beds: Fundamentals and Applications, Cambridge University Press, Cambridge, 2011, pp. 82-104.

[32] V.S. Sutkar, T.J.K. van Hunsel, N.G. Deen, V. Salikov, S. Antonyuk, S. Heinrich, J.A.M. Kuipers, Experimental investigations of a pseudo-2D spout fluidized bed with draft plates, Chem. Eng. Sci. 102 (2013) 524-543. 